\title{
Urban Seismic Risk Evaluation: A Holistic Approach
}

\author{
MARTHA-LILIANA CARREÑO ${ }^{1, \star}$, OMAR D. CARDONA $^{2}$ and ALEX \\ H. BARBAT ${ }^{1}$ \\ ${ }^{1}$ Universidad Politécnica de Cataluña. Campus Norte., C/ Gran Capitán sn, Mod. C1, Barcelona \\ 08034, Spain; ${ }^{2}$ Universidad Nacional de Colombia, Campus Palogrande, IDEA, Cra. 27 \\ No. 64-60, Manizales, Colombia
}

(Received: 18 August 2005; accepted: 3 February 2006)

\begin{abstract}
Risk has been defined, for management purposes, as the potential economic, social and environmental consequences of hazardous events that may occur in a specified period of time. However, in the past, the concept of risk has been defined in a fragmentary way in many cases, according to each scientific discipline involved in its appraisal. From the perspective of this article, risk requires a multidisciplinary evaluation that takes into account not only the expected physical damage, the number and type of casualties or economic losses, but also the conditions related to social fragility and lack of resilience conditions, which favour the second order effects (indirect effects) when a hazard event strikes an urban centre. The proposed general method of urban risk evaluation is multi hazard and holistic, that is, an integrated and comprehensive approach to guide decision-making. The evaluation of the potential physical damage (hard approach) as the result of the convolution of hazard and physical vulnerability of buildings and infrastructure is the first step of this method. Subsequently, a set of social context conditions that aggravate the physical effects are also considered (soft approach). In the method here proposed, the holistic risk evaluation is based on urban risk indicators. According to this procedure, a physical risk index is obtained, for each unit of analysis, from existing loss scenarios, whereas the total risk index is obtained by factoring the former index by an impact factor or aggravating coefficient, based on variables associated with the socioeconomic conditions of each unit of analysis. Finally, the proposed method is applied in its single hazard form to the holistic seismic risk evaluation for the cities of Bogota (Colombia) and Barcelona (Spain).
\end{abstract}

Key words: holistic approach, risk evaluation, seismic risk, socio-economic vulnerability

\section{The Notion of Risk}

Many of the conceptual approaches of risk had their origin in the studies on technological hazards and some of them were extrapolated to the field of natural disaster risk. Perhaps, the first specialized researches on the topic of natural disasters started in the early 1960's based on the pioneering contributions of Gilbert White (1964) from the view of the ecology and

^ Author for correspondence: E-mail: liliana@cimne.upc.edu 
geography. Sociologists as Enrico Quarantelli (1988) and Dynes and Drabek (1994) since 1963 devoted efforts to explain the social response to disasters following analogies with response in case of nuclear attacks. Geographers as Robert Kates (1971) and Roger Kasperson et al. (1988) and physicist Christopher Hohenemser focused their research in both natural and nuclear risks. The point of view of civil engineering has been materialized in the developments performed in the field of physical risk. Thus, starting from the work on damage assessment of Whitman (1973), innumerable methodologies devoted to the physical seismic risk assessment have been developed all over the world. Later, this process evolved towards a more integrated vision of the seismic risk, incorporating others of its aspects (Coburn and Spence 1992) until reaching the widespreaded HAZUS (FEMA, 1999) methodology, now available for multi hazard risk assessment. During the 1990 's, stimulated by the International Decade for Natural Disaster Reduction, IDNDR, many researches dealing with risks and disasters were developed around the world. The topic gained importance and it is being increasingly recognized that the terms hazard, vulnerability and risk have had different meanings and implications from both the methodological and practical angles (Cardona, 2004 .

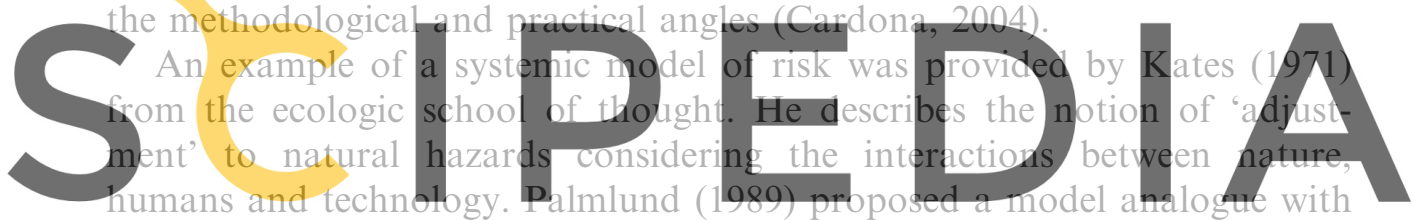

the classic structure of a Greek tragedy (with actors, scenario drama and Register for free at https//www scipedia.com to download the version without the watermark

social perspective. A classic contextual or structural explanation, where risk is seen as an attribute of social structures, is that proposed by Douglas and Wildavsky (1982). A cultural theory of risk is proposed by Rayner (1992) while approaches of the Political Economy school are given by Westgate and O'Keefe (1976), Wijkman and Timberlake (1984), Susman et al. (1984) and Chambers (1989). The contributions of Wisner (1993), Cannon (1994), Blaikie et al. (1996) and of members of the Network for the Social Study of Disaster Prevention in Latin America (La Red) (Maskrey, 1994; Lavell, 1996; Cardona, 1996; Mansilla, 1996) may also be considered constructivist, emphasizing the social construction of vulnerability and risk. One of the conceptual contributions that derived in a multidisciplinary approach was made by Wilches-Chaux (1989). He proposed different classes of vulnerabilities (cultural, environmental, social, economic, physical, etc.).

The report Natural Disasters and Vulnerability Analysis (UNDRO, 1980), based on the Expert Meeting held in 1979, proposed the unification of disaster related definitions as hazard $(H)$, vulnerability $(V)$, exposed 
elements $(E)$ and risk $(R)$ and suggested one expression to associating them, that is considered a standard at present,

$$
R=E \cdot H \cdot V
$$

Based on this formulation several methodologies for risk assessment have been developed from different perspectives in the last decades, and recently a holistic or multidisciplinary approach for the case of urban centres (Cardona and Hurtado, 2000; Masure, 2003).

Cardona (2001) developed a conceptual framework and a model for seismic risk analysis of a city from a holistic perspective. It considers both "hard" and "soft" risk variables of the urban centre, taking into account exposure, socio-economic characteristics of the different localities (units) of the city and their disaster coping capacity or degree of resilience. The model was made to guide the decision-making in risk management, helping to identify the critical zones of the city and their vulnerability from different professional disciplines.
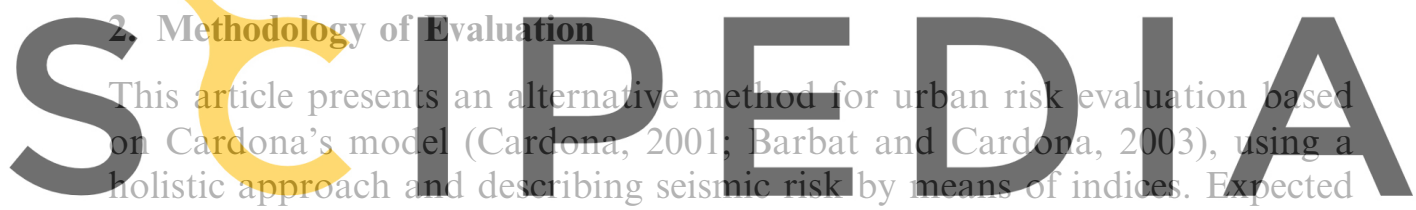

building damage and losses in the infrastructure, obtained from future

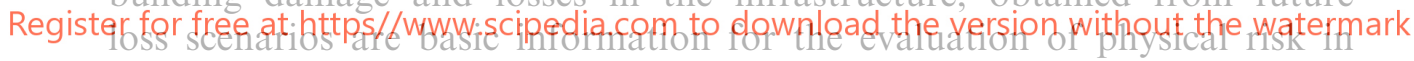

each unit of analysis. Starting from these data, a physical damage index is obtained.

The proposed method is developed for a multi-hazard evaluation and therefore it is necessary to dispose of physical damage estimations for all the significant hazards. Often, when historical information is available, the principal hazard can be usually identified and thus the most potential critical situation.

The holistic evaluation of risk by means of indices is achieved affecting the physical risk with an impact factor, obtained from contextual conditions, such as the socio-economic fragility and the lack of resilience, that aggravate initial physical loss scenario. Available data about these conditions at urban level are necessary to apply the method. An explanation of the model is made ahead and also some examples of application for the cities of Bogota, Colombia, and Barcelona, Spain, are described to illustrate the benefits of this approach that contributes to the effectiveness of risk management, inviting to the action identifying the hard and soft weaknesses of the urban centre. Figure 1 shows the theoretical framework of the alternative model. 


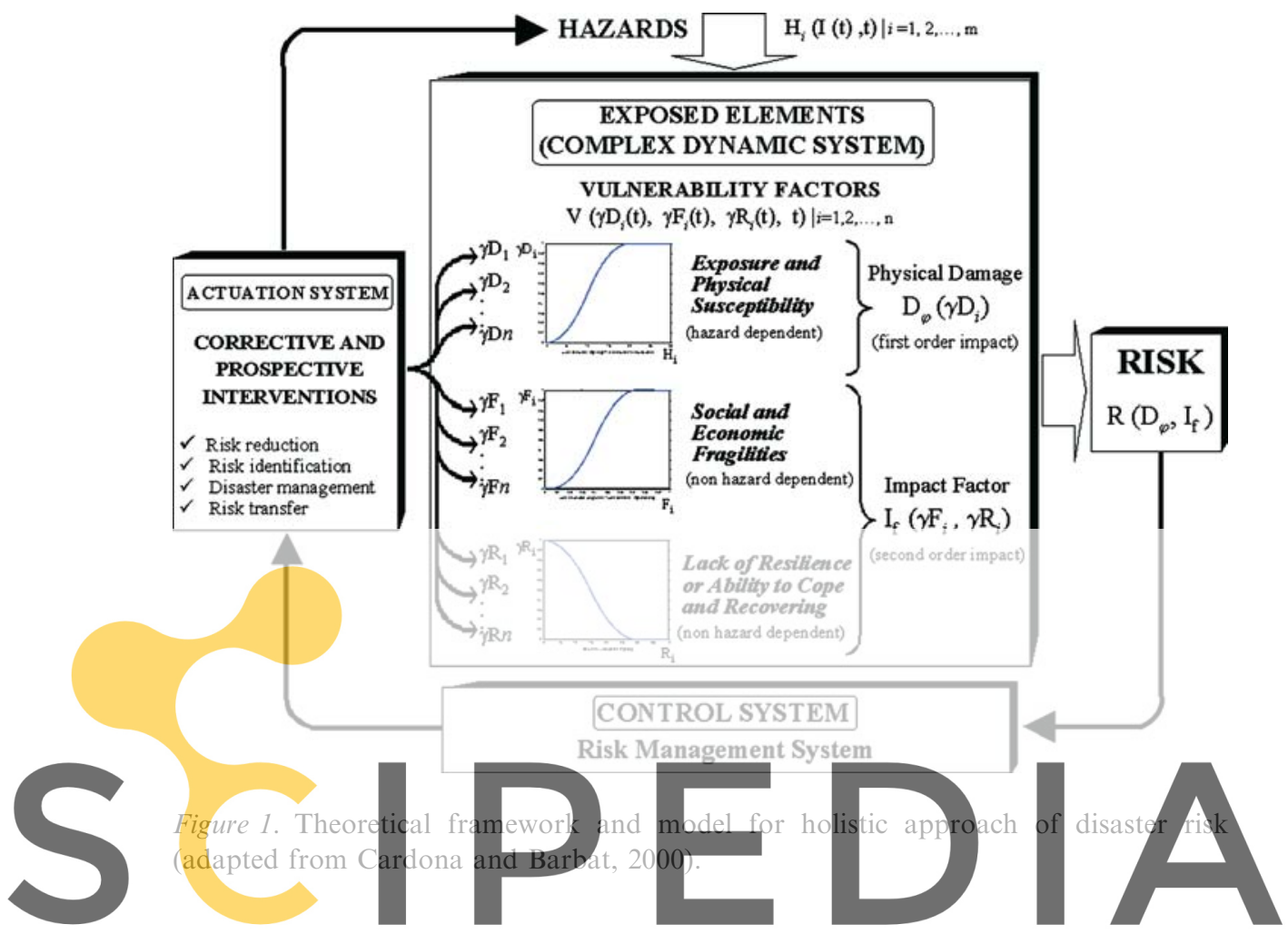

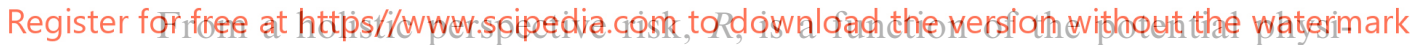
cal damage, $D_{j}$, and an impact factor, $I_{f}$. The former is obtained from the susceptibility of the exposed elements, $\gamma_{\mathrm{Di}}$, to hazards, $H_{\mathrm{i}}$, regarding their potential intensities, $I$, of events in a period of time $t$, and the latter depends on the social fragilities, $\gamma_{\mathrm{Fi}}$, and the issues related to lack of resilience, $\gamma_{\mathrm{Ri}}$, of the disaster prone socio-technical system or context. Using the meta-concepts of the theory of control and complex system dynamics to reduce risk, it is necessary to intervene in corrective and prospective way the vulnerability factors and, when it is possible, the hazards directly. Then risk management requires a system of control (institutional structure) and an actuation system (public policies and actions) to implement the changes needed on the exposed elements or complex system where risk is a social process.

In this paper the proposed holistic evaluation of risk is performed using a set of input variables, herein denominated descriptors. They reflect the physical risk and the aggravating conditions that contribute to the potential impact. Those descriptors, which will be discussed later, are obtained from the loss scenarios and from socio-economic and coping capacity information of the exposed context (Carreño et al. 2005). 
The model of holistic urban risk evaluation proposed in this paper improves conceptual and methodological aspects of the first proposal of Cardona (2001), refining the applied numerical techniques and turning it into a more versatile tool. The conceptual improvements provide a more solid theoretical and analytical support to the new model, eliminating unnecessary and dubious aspects of the previous method and giving more transparency and applicability in some cases. Cardona's model allows the evaluation of the seismic risk in an urban center taking into account the characteristics of the physical risk, seismic hazard, physical exposure, socio-economical fragility and lack of resilience, what permits to identify those characteristics of the city that increase the level of risk and also the critical areas. This model studies different types of information by means of indicators and uses a normalization process of the results based on the mean and on the standard deviation which is applied to each indicator. As a consequence, the results obtained with Cardona's method allow a comparison of the holistic seismic risk among the different areas of a city in a relative way, but not a comparison in absolute terms with other urban areas. Cardona's model uses of a neuro-fuzzy System, with fuzzy sets which identify the lingutistic qualifications of the
descriptors, but the necessary in do not exist.
The new method proposed in this article conserves the approach based
on indicators, but it improves the procedure of normalization and calcu-

lates the final indices in an absolute (non relative) manner. This feature Register for free at https// wwW.scipedia.com to download the version without the watermark raciltates the comparison of risk among urban centers. The exposure and the seismic hazard have been eliminated in the method proposed in this paper because they have been included into the physical risk variables calculation. The descriptor of population density, a component of the exposure in Cardona's model is now included as a descriptor of social fragility. The new approach preserves the use of indicators and fuzzy sets or membership functions, proposed originally by Cardona, but in a different way. Other improvements of the proposed model refer to the units of some of the descriptors; in certain cases it is more important to normalize the input values respecting the population than with respect of the area of the studied zone. This is, for example, the case of the number of hospital beds existing in the studied urban area.

The socio-economic fragility and the lack of resilience are a set of factors (related to indirect or intangible effects) that aggravate the physical risk (potential direct effects). Thus, the total risk depends on the direct effect, or physical risk, and the indirect effects expressed as a factor of the direct effects. Therefore, the total risk can be expressed as follows:

$$
R_{\mathrm{T}}=R_{\mathrm{F}}(1+F)
$$


expression known as the Moncho's Equation in the field of disaster risk indicators, where $R_{\mathrm{T}}$ is the total risk index, $R_{\mathrm{F}}$ is the physical risk index and $F$ is the impact factor. This coefficient, $F$, depends on the weighted sum of a set of aggravating factors related to the socio-economic fragility, $F_{\mathrm{FSi}}$, and the lack of resilience of the exposed context, $F_{\mathrm{FRj}}$

$$
F=\sum_{i=1}^{m} w_{\mathrm{FSi}} \times F_{\mathrm{FSi}}+\sum_{j=1}^{n} w_{\mathrm{FRj}} \times F_{\mathrm{FRj}}
$$

where $w_{\mathrm{FSi}}$ and $w_{\mathrm{FRj}}$ are the weights or influences of each $i$ and $j$ factors and $m$ and $n$ are the total number of descriptors for social fragility and lack of resilience respectively.

The aggravating factors $F_{\mathrm{FSi}}$ and $F_{\mathrm{FRj}}$ are calculated using transformation functions shown in the Figures 2 and 3. These functions standardise the gross values of the descriptors transforming them in commensurable factors. The weights $w_{\mathrm{FSi}}$ and $w_{\mathrm{FRj}}$ represent the relative importance of each factor and are calculated by means of the Analytic Hierarchy Process (AHP), which is used to derive ratio scales from both discrete and continuous paired comparisons (Saaty, 2001). This process, completely
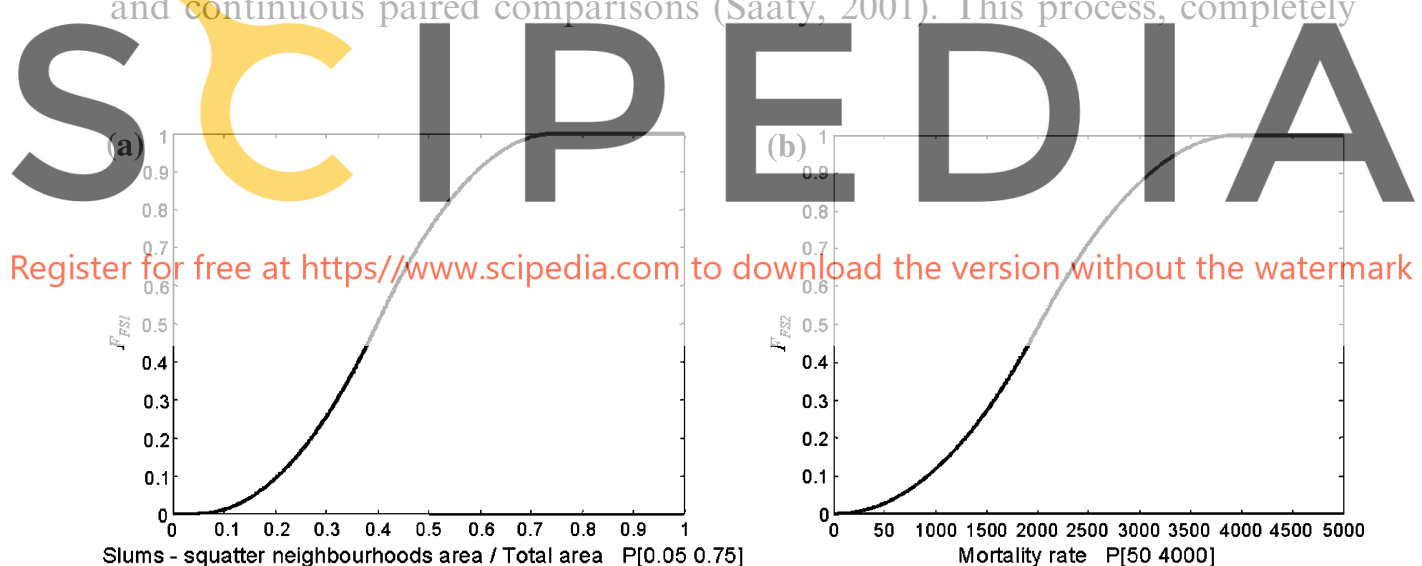

Slums - squatter neighbourhoods area / Total area $P[0.050 .75]$
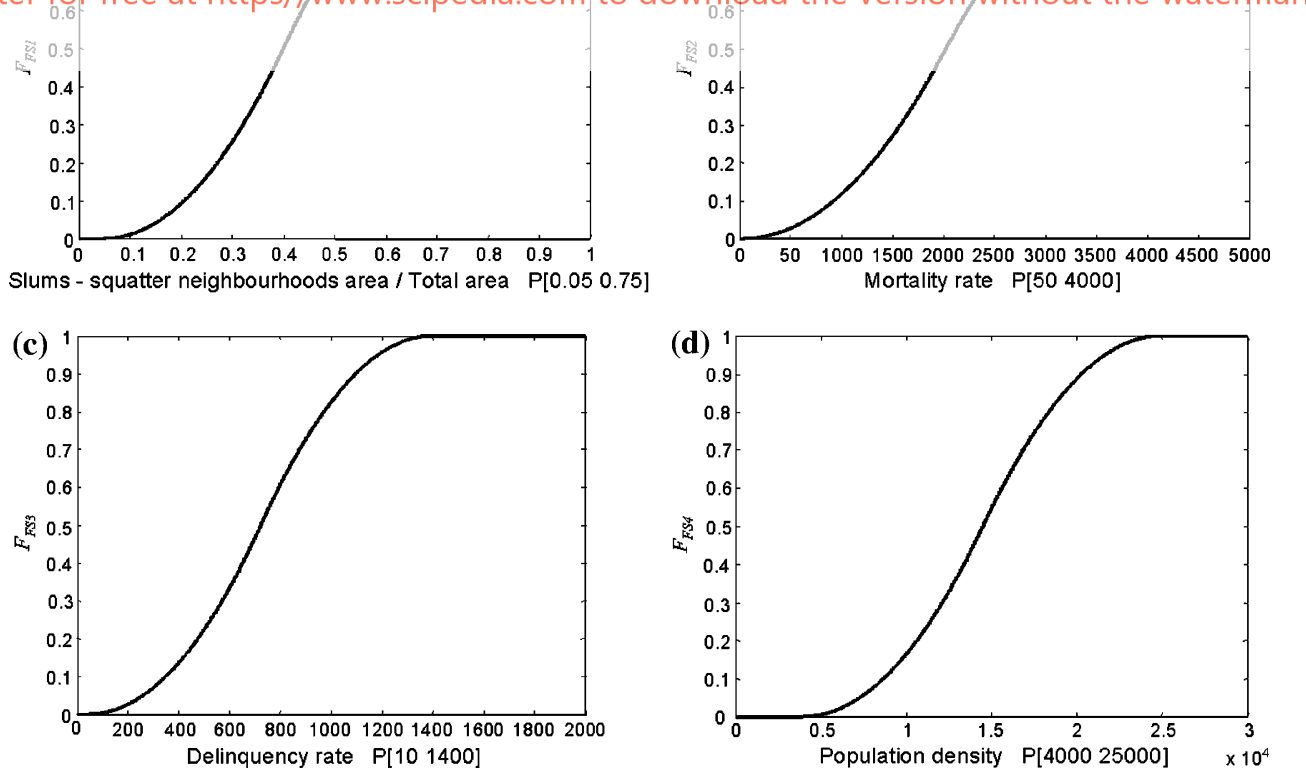

Figure 2. Transformation functions used to standardise the social fragility factors. 

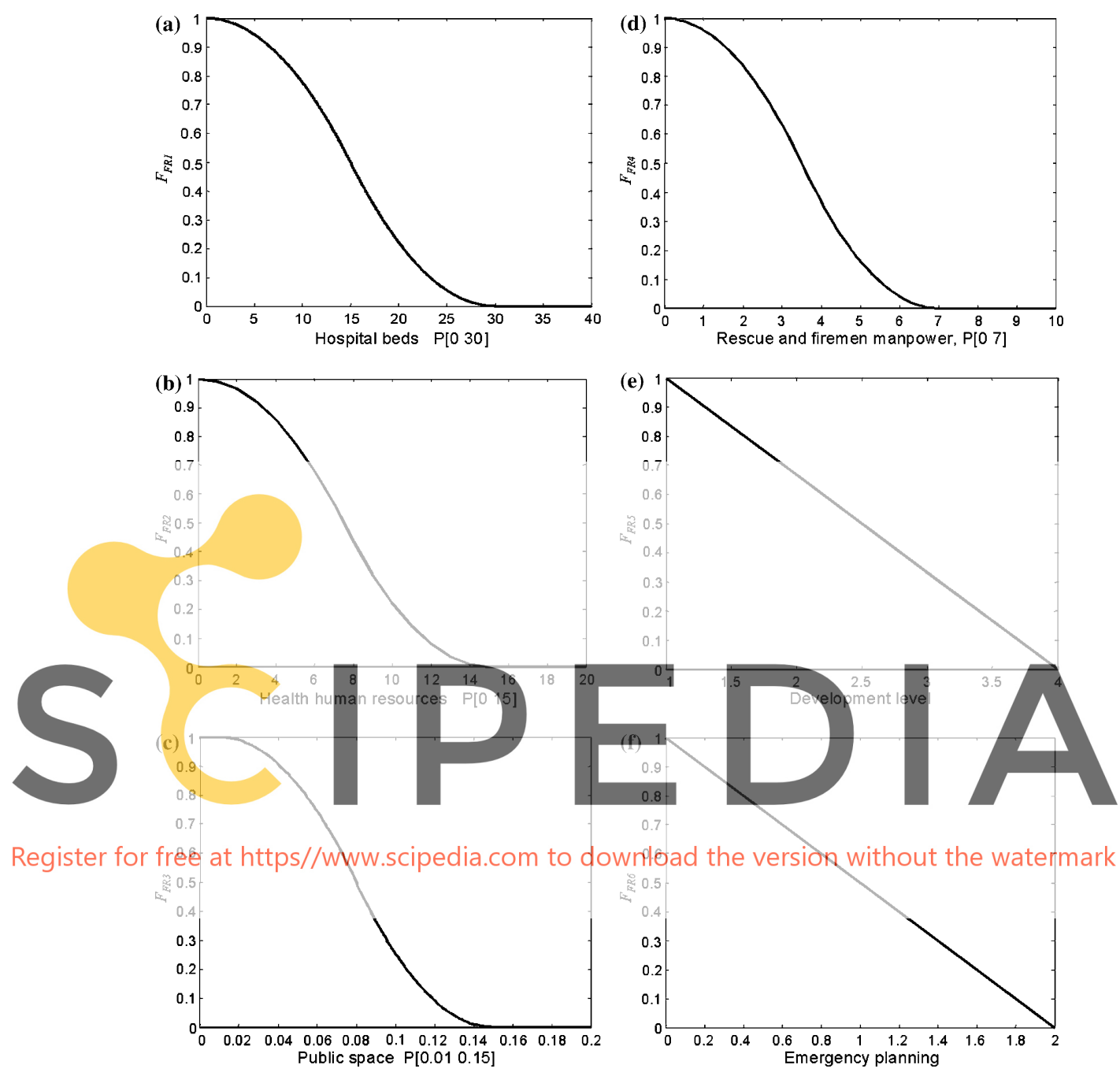

Figure 3. Transformation functions used to standardise the lack of resilience factors.

explained in the Appendix, has been performed starting from the experts opinions collected in Tables A.1 and A.3 by means of the Delphi method. This is the most adequate way of judging the relative importance of variables having different nature and calculating their relative weights.

The physical risk, $R_{\mathrm{F}}$, is evaluated in the same way, using the transformation functions shown in the Figure 4.

$$
R_{\mathrm{F}}=\sum_{i=1}^{p} W_{\mathrm{RFi}} \times F_{\mathrm{RFi}}
$$



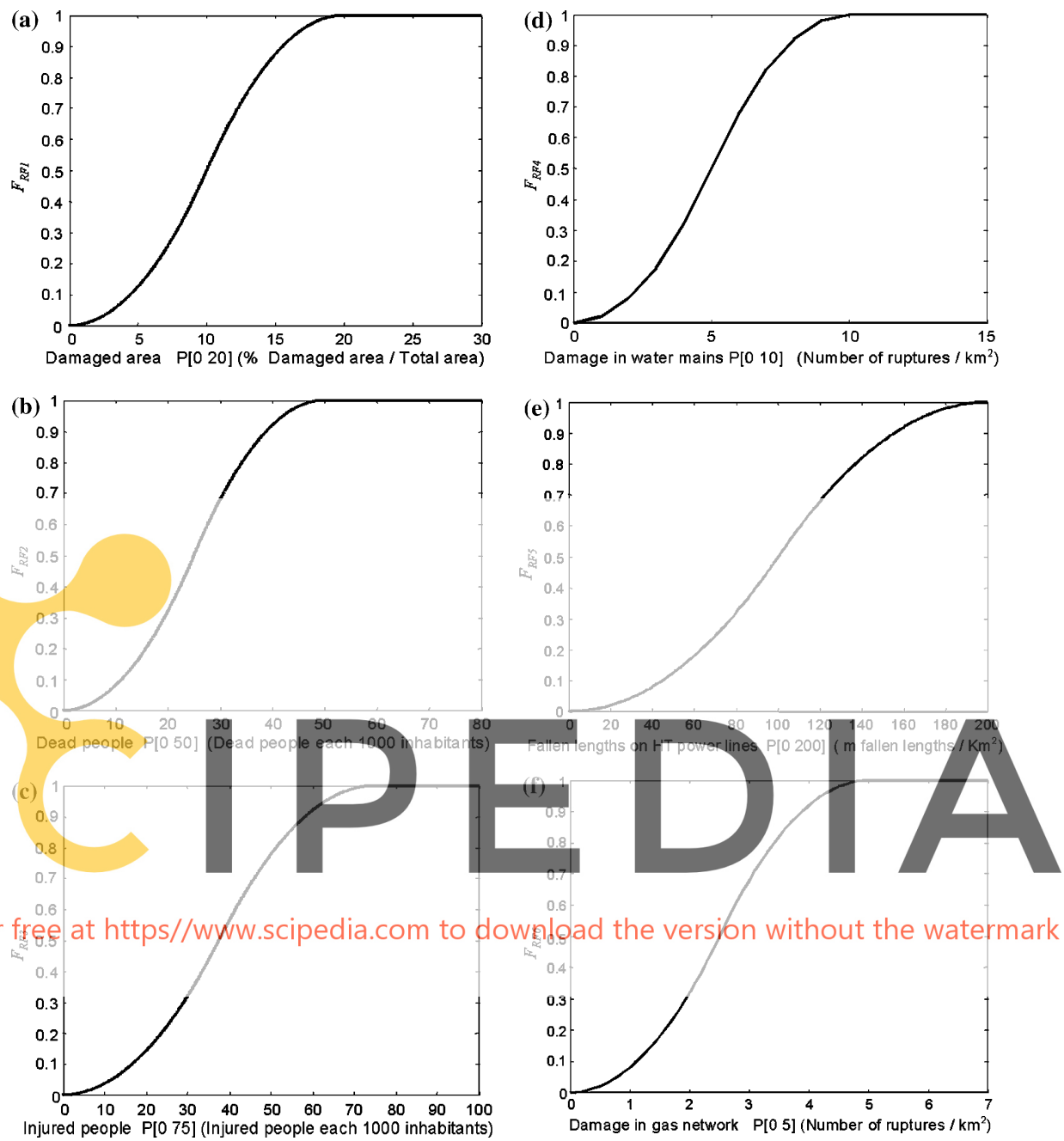

Register for frege at https//wyw.scipedia.com to downdgad the version without the watermark

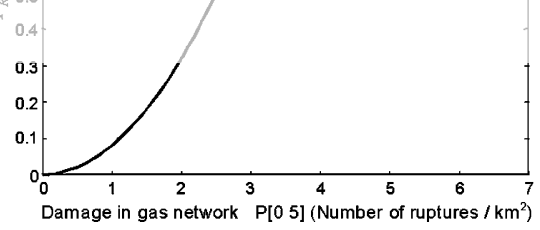

Figure 4. Transformation functions used to standardise the physical risk factors.

where $p$ is the total number of descriptors of physical risk index, $F_{\mathrm{RFi}}$ are the component factors and $w_{\mathrm{RFi}}$ are their weights respectively. The factors of physical risk, $F_{\mathrm{RFi}}$, are calculated using the gross values of physical risk descriptors such as the number of deaths, injured or the destroyed area, and so on. It has to be mentioned that the calculation of physical risk scenarios is not the objective of the methodology developed in this paper, but the physical risk index is obtained starting from existing loss evaluations.

It is estimated that the indirect effects of hazard events, sized by the factor $F$ in Equation (2), can be of the same order than the direct effects. According to the Economic Commission for Latin America and the Caribbean (Zapata, 
2004), it is estimated that the indirect economic effects of a natural disaster depend on the type of phenomenon. The order of magnitude of the indirect economic effects for a 'wet' disaster (as one caused by a flood) could be of 0.50 to 0.75 of the direct effects. In the case of a 'dry' disaster (caused by an earthquake, for example), the indirect effects could be about the 0.75 to 1.00 of the direct effects, due to the kind of damage (destruction of livelihoods, infrastructure, housing, etc.). This means that the total risk, $R_{\mathrm{T}}$, could be between 1.5 and 2 times $R_{\mathrm{F}}$. In this method, the maximum value selected was the latter. For this reason, the impact factor, $F$, takes values between 0 and 1 in Equation (2), in this case.

In order to develop the transformation functions, sigmoid functions were used in most of the cases (see Figures 2-4). There are two exceptions in the case of the lack of resilience, the descriptors of the level of development of the community and of the emergency planning or preparedness, for which a linear relation was assumed. Once decided the shape of these functions, all their maximum and minimum values (corresponding to the values 1 or 0 of each factor) were fixed using existing information about past disasters as well as the opinion of American and European experts. Table I gives the variables used to describe the social fragility and the rack of resilience in the estimation of the impact factor $F$. The transformation functions describe the intensity of the risk for each descriptor. For number of deaths by natural causes for each 10,000 inhabitants, stggest that the aggravation for this factor is minimal if it takes a value smaller Registerfor free at https/www.scipedia, com to download the version without the water.mark than 50 deaths for each 10,000 inhabitants, and the aggravation 1s maximal if the value is bigger than 4,000 deaths for each 10,000 inhabitants. Another example is the case of the damaged built area; the corresponding

Table I. Descriptors used to evaluate the impact factor, $F$.

\begin{tabular}{ll}
\hline Aspect & Descriptor \\
\hline Social fragility & Slums-squatter neighbourhoods \\
& Mortality rate \\
& Delinquency rate \\
& Social disparity index \\
Lack of resilience & Population density \\
& Hospital beds \\
& Health human resources \\
& Public space \\
& Rescue and firemen manpower \\
& Development level \\
& Preparedness emergency planning \\
\hline
\end{tabular}


transformation function defines a minimum risk (0) when this descriptor is zero and, the maximum risk (1) was established for a potential damaged area of $20 \%$ of the constructed one according to the experts opinion.

Figures 2-4 show the values of the descriptors in the $x$-axis of the transformation functions. The corresponding factors, or scaled values, are given in the $y$-axis. Table II presents the initial measurement units of each descriptor of social fragility and resilience. Table III shows the descriptors of the physical risk. The factors for a city are obtained in each case using the transformation functions of the aforesaid figures and the variables

Table II. Aggravating descriptors, their units and identifiers.

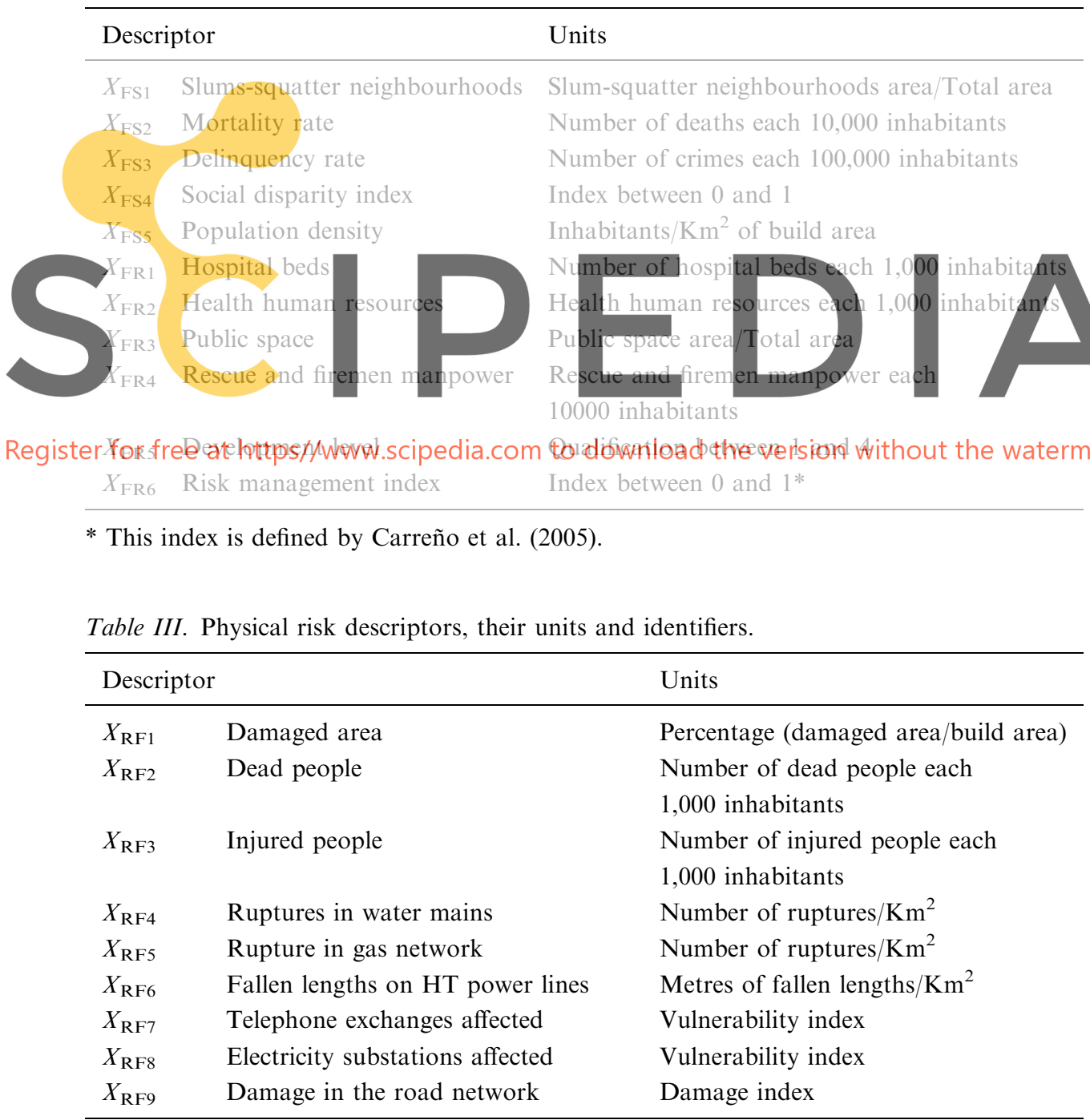


with the units of tables above-mentioned. Figure 5 shows the process of calculation of the total risk index for the units of analysis, which could be districts, municipalities, communes or localities.

\section{Examples of Application}

\subsection{SEISMIC RISK OF BOGOTA}

In Bogota, the capital of Colombia, the localities or mayorships are political-administrative subdivisions of the urban territory, with clear competences in financing and application of resources. They were created with the objective of attending in an effective way the needs of the population of each territory. Since 1992, Bogota has 20 localities which can be seen in Figure 6: Usaquén, Chapinero, Santafé, San Cristóbal, Usme, Tunjuelito, Bosa, Ciudad Kennedy, Fontibón, Engativa, Suba, Barrios Unidos, Teusaquillo, Mártires, Antonio Nariño, Puente Aranda, Candelaria, Rafael Uribe, Ciudad Bolívar and Sumapaz. In this study, only 19 of these

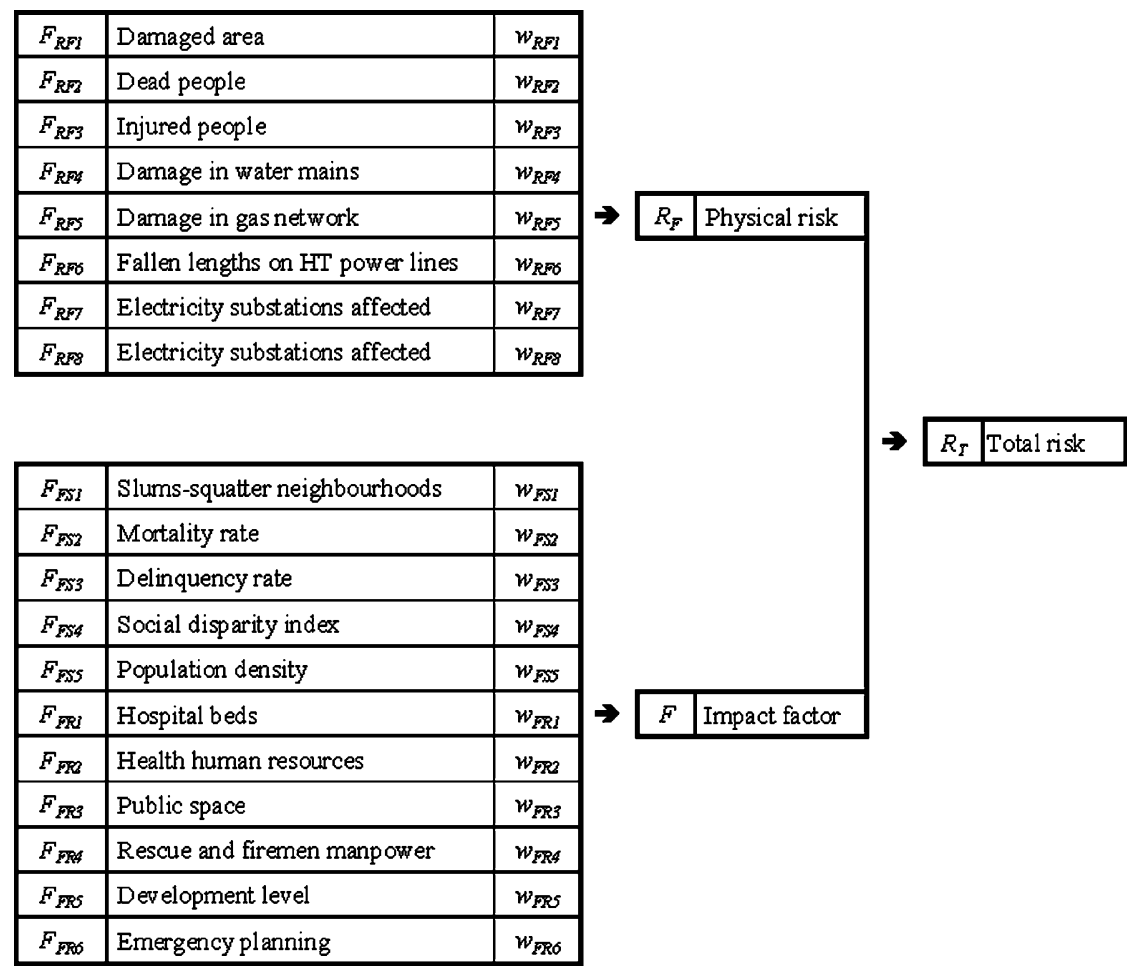

Figure 5. Factors of physical risk, social fragility and lack of resilience and their weights. 


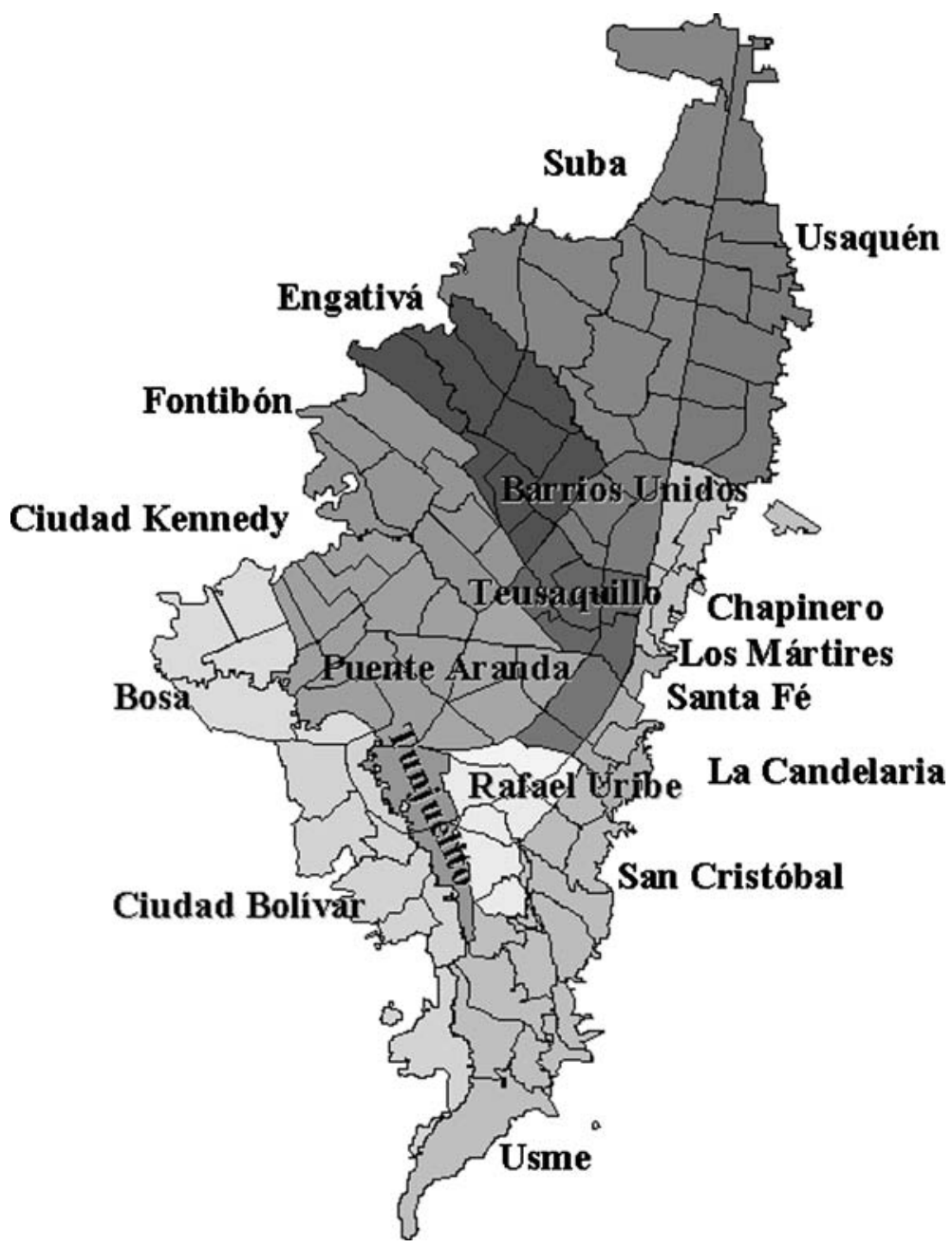

Figure 6. Political-administrative division of Bogota, Colombia.

localities are considered, because the locality of Sumapaz corresponds to the rural area. These localities are subdivided in 117 territorial units (UPZ).

As it is well known, the seismic hazard is the most significant threat for Bogota. The scenario of seismic physical risk illustrated in Figure 7 (Universidad de Los Andes, 2005) was used as a starting point for the application of the model. It displays the percentage of the damaged area in predefined cells considering that an earthquake with a magnitude Ms of 7.4 and a return period of 500 years occurs in the frontal fault of the Western Mountains (Universidad de Los Andes, 2005). The seismic risk scenario was calculated by means of building by building simulations and, 


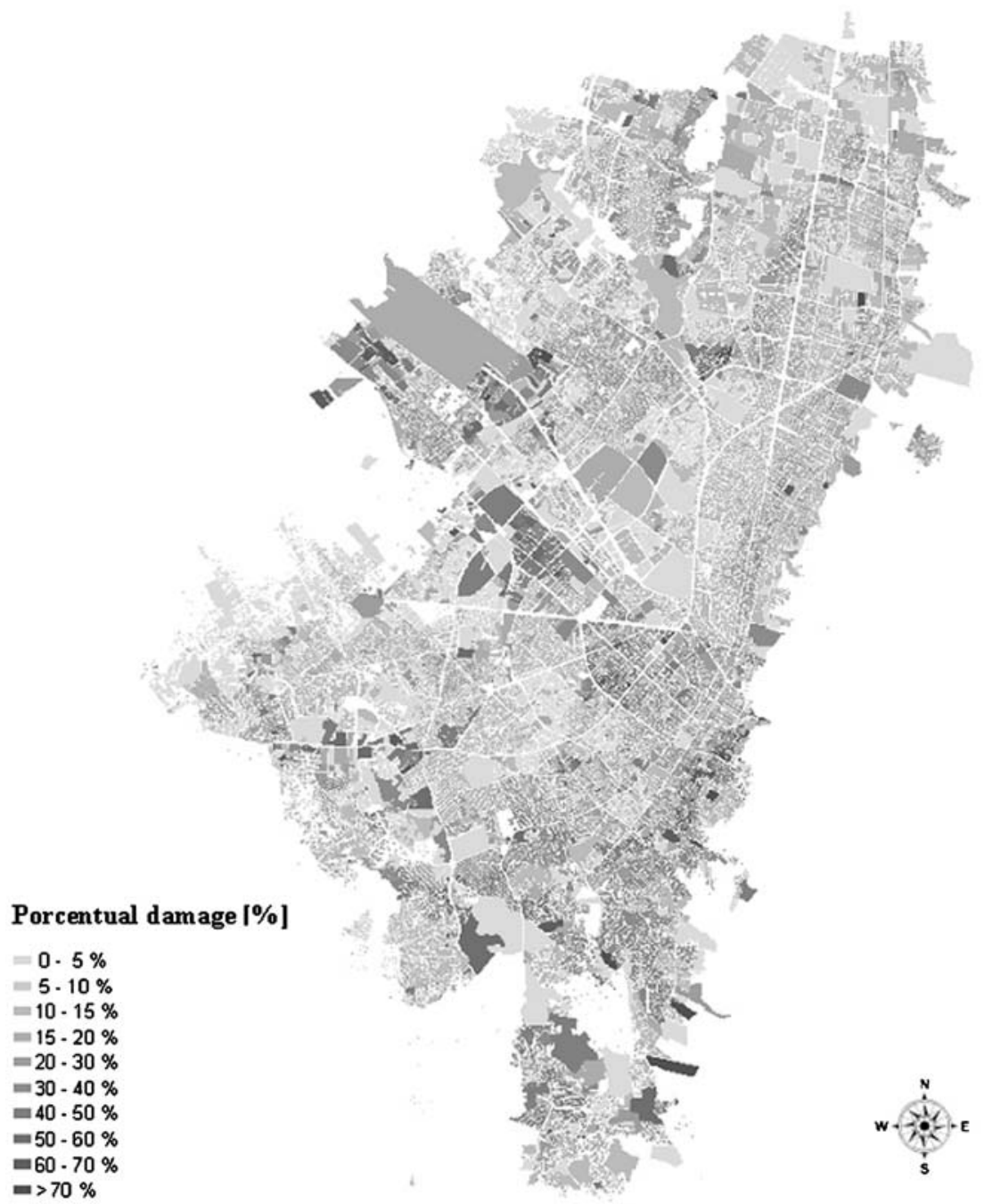

Figure 7. One scenario of physical seismic risk (Universidad de los Andes, 2005).

thus, the descriptors of the physical risk can be obtained for each UPZ. Nevertheless, the information regarding the aggravating factors has been calculated for each locality and not for each UPZ, as it will be seen later.

Tables IV and V show the weights computed using the AHP, as it is described in the Appendix, for the components of the physical risk and for the aggravating factors, respectively.

Tables VI and VIII show the values of the descriptors used in this application, which represent the physical risk and the social fragility and the lack of resilience of the city, respectively. Table VII shows the values 
Table IV. Weights for the factors of the physical risk.

\begin{tabular}{lll}
\hline Factor & Weight & Weight value \\
\hline$F_{\mathrm{RF} 1}$ & $w_{\mathrm{RF} 1}$ & 0.31 \\
$F_{\mathrm{RF} 2}$ & $w_{\mathrm{RF} 2}$ & 0.10 \\
$F_{\mathrm{RF} 3}$ & $w_{\mathrm{RF} 3}$ & 0.10 \\
$F_{\mathrm{RF} 4}$ & $w_{\mathrm{RF} 4}$ & 0.19 \\
$F_{\mathrm{RF} 5}$ & $w_{\mathrm{RF} 5}$ & 0.11 \\
$F_{\mathrm{RF} 6}$ & $w_{\mathrm{RF} 6}$ & 0.11 \\
$F_{\mathrm{RF} 7}$ & $w_{\mathrm{RF} 7}$ & 0.04 \\
$F_{\mathrm{RF} 8}$ & $w_{\mathrm{RF} 8}$ & 0.04 \\
\hline
\end{tabular}

Table $V$. Weights for the factors of the aggravating conditions.

\begin{tabular}{lll}
\hline Factor & Weight & Weight value \\
\hline$F_{\mathrm{FS} 1}$ & $w_{\mathrm{FS} 1}$ & 0.18 \\
$F_{\mathrm{FS} 2}$ & $w_{\mathrm{FS} 2}$ & 0.04 \\
$F_{\mathrm{FS} 3}$ & $w_{\mathrm{FS} 3}$ & 0.04 \\
$F_{\mathrm{FS} 4}$ & $w_{\mathrm{FS} 4}$ & 0.18 \\
$F_{\mathrm{FS} 5}$ & $w_{\mathrm{FS} 5}$ & 0.18 \\
$F_{\mathrm{FR} 1}$ & $w_{\mathrm{FR} 1}$ & 0.06 \\
$F_{\mathrm{FR} 2}$ & $w_{\mathrm{FR} 2}$ & 0.06 \\
$F_{\mathrm{FR} 3}$ & $w_{\mathrm{FR} 3}$ & 0.04 \\
$F_{\mathrm{FR} 4}$ & $w_{\mathrm{FR} 4}$ & 0.03 \\
$F_{\mathrm{FR} 5}$ & $w_{\mathrm{FR} 5}$ & 0.09 \\
$F_{\mathrm{FR} 6}$ & $w_{\mathrm{FR} 6}$ & 0.09 \\
\hline
\end{tabular}

of the factors of physical risk obtained by applying the functions of the Figure 4. Table IX shows the aggravating factors of the indirect effects due to the social fragility and the lack of resilience; they are obtained by the applying the functions of Figures 2 and 3. The physical risk index, $R_{\mathrm{F}}$, and the impact factor, $F$, are also indicated in these tables. In addition, the average values for the city are shown. They have been calculated normalizing by the density of population. Table $\mathrm{X}$ shows the results for the physical risk, the impact factor and the total risk of each locality and the average values for the city.

Figures 8-12 display graphically the results of the holistic evaluation of the seismic risk of Bogota using the proposed model. The average values of the physical risk and total risk by locality are shown in Figures 10 and 12. These figures show that the locality of Candelaria has the most critical situation from the point of view of the physical and 
Table VI. Descriptor values of the physical risk, $R_{\mathrm{F}}$.

\begin{tabular}{|c|c|c|c|c|c|c|c|c|c|c|}
\hline UPZ & Nombre UPZ & Localidad & $X_{\mathrm{RF} 1}$ & $X_{\mathrm{RF} 2}$ & $X_{\mathrm{RF} 3}$ & $X_{\mathrm{RF} 4}$ & $X_{\mathrm{RF} 5}$ & $X_{\mathrm{RF} 6}$ & $X_{\mathrm{RF} 7}$ & $X_{\mathrm{RF} 8}$ \\
\hline 1 & Paseo los Libertadores & San Cristóbal & 8.5 & 0 & 0 & 0.96 & 0.17 & 33.69 & 0.68 & 0.90 \\
\hline 2 & La Academia & Suba & 5.6 & 0 & 1 & 0.81 & 0.17 & 19.14 & 0.66 & 0.77 \\
\hline 3 & Guaymaral & Suba & 5.7 & 1 & 5 & 0.93 & 0.18 & 19.14 & 0.66 & 0.77 \\
\hline 9 & Verbenal & Usaquén & 8.4 & 1 & 3 & 0.65 & 0.16 & 23.87 & 0.7 & 0.83 \\
\hline 10 & La Uribe & Usaquén & 12.6 & 1 & 4 & 0.85 & 0.16 & 23.87 & 0.7 & 0.83 \\
\hline 11 & San Cristóbal Norte & Usaquén & 12.3 & 1 & 4 & 0.67 & 0.14 & 23.87 & 0.7 & 0.83 \\
\hline 12 & Toberin & Usaquén & 13 & 6 & 19 & 1.08 & 0.23 & 23.87 & 0.7 & 0.83 \\
\hline 13 & Los Cedros & Usaquén & 12.8 & 8 & 17 & 0.83 & 0.20 & 23.87 & 0.7 & 0.83 \\
\hline$\ldots$ & $\cdots$ & $\ldots$ & $\ldots$ & $\ldots$ & $\ldots$ & $\ldots$ & $\ldots$ & $\ldots$ & $\ldots$ & $\ldots$ \\
\hline 110 & Ciudad Salitre Occidental & Fontibón & 10 & 11 & 21 & 0.89 & 0.16 & 5.49 & 0.64 & 0.7 \\
\hline 111 & Puente Aranda & Puente Aranda & 21.6 & 55 & 181 & 1.11 & 0.27 & 20.19 & 0.69 & 0.7 \\
\hline 112 & Granjas Techo & Fontibón & 30.4 & 102 & 337 & 0.94 & 0.22 & 5.49 & 0.64 & 0.7 \\
\hline 113 & Bavaria & Kennedy & 15.5 & 22 & 57 & 1.14 & 0.24 & 10.80 & 0.54 & 0.7 \\
\hline 114 & Modelia & Fontibón & 11.7 & 2 & 7 & 1.12 & 0.29 & 5.49 & 0.64 & 0.7 \\
\hline 115 & Capellania & Fontibón & 27.2 & 23 & 74 & 1.24 & 0.31 & 5.49 & 0.64 & 0.7 \\
\hline 116 & Alamos & Negativa & 36.3 & 21 & 63 & 1.23 & 0.33 & 2.82 & 0.66 & 0.8 \\
\hline 117 & Aeropuerto El Dorado & Fontibón & 16.4 & 2 & 6 & 1.27 & 0.34 & 5.49 & 0.64 & 0.7 \\
\hline
\end{tabular}


Table VII. Factors, $F_{\mathrm{RF}}$, and the physical risk index, $R_{\mathrm{F}}$.

\begin{tabular}{|c|c|c|c|c|c|c|c|c|c|c|c|}
\hline UPZ & Nombre UPZ & Localidad & $F_{\mathrm{RF} 1}$ & $F_{\mathrm{RF} 2}$ & $F_{\mathrm{RF} 3}$ & $F_{\mathrm{RF} 4}$ & $F_{\mathrm{RF} 5}$ & $F_{\mathrm{RF} 6}$ & $F_{\mathrm{RF} 7}$ & $F_{\mathrm{RF} 8}$ & $R_{\mathrm{F}}$ \\
\hline 1 & Paseo los Libertadores & SanCristóbal & 0.361 & 0 & 0 & 0.019 & 0.00243 & 0.058 & 0.68 & 0.9 & 0.188 \\
\hline 2 & La Academia & Suba & 0.157 & 0 & 0.000356 & 0.0143 & 0.0024 & 0.0181 & 0.66 & 0.77 & 0.113 \\
\hline 3 & Guaymaral & Suba & 0.162 & 0.0008 & 0.00889 & 0.018 & 0.00249 & 0.0181 & 0.66 & 0.77 & 0.116 \\
\hline 9 & Verbenal & Usaquén & 0.353 & 0.0008 & 0.0032 & 0.00985 & 0.00201 & 0.0288 & 0.7 & 0.83 & 0.179 \\
\hline 10 & La Uribe & Usaquén & 0.726 & 0.0008 & 0.00569 & 0.0157 & 0.00209 & 0.0288 & 0.7 & 0.83 & 0.298 \\
\hline 11 & San Cristóbal Norte & Usaquén & 0.704 & 0.0008 & 0.00569 & 0.0105 & 0.00158 & 0.0288 & 0.7 & 0.83 & 0.290 \\
\hline 12 & Toberin & Usaquén & 0.755 & 0.0288 & 0.128 & 0.0229 & 0.00414 & 0.0288 & 0.7 & 0.83 & 0.324 \\
\hline 13 & Los Cedros & Usaquén & 0.741 & 0.0512 & 0.103 & 0.0148 & 0.00332 & 0.0288 & 0.7 & 0.83 & 0.318 \\
\hline$\ldots$ & $\cdots$ & $\ldots$ & $\ldots$ & $\ldots$ & $\ldots$ & $\ldots$ & $\ldots$ & & $\ldots$ & $\ldots$ & $\ldots$ \\
\hline 110 & Ciudad Salitre Occital. & Fontibón & 0.5 & 0.0968 & 0.157 & 0.0168 & 0.00215 & 0.00125 & 0.64 & 0.7 & 0.242 \\
\hline 111 & Puente Aranda & Pte.Aranda & 1 & 1 & 1 & 0.0239 & 0.00571 & 0.02 & 0.69 & 0.7 & 0.584 \\
\hline 112 & Granjas Techo & Fontibón & 1 & 1 & 1 & 0.0182 & 0.00371 & 0.00125 & 0.64 & 0.7 & 0.579 \\
\hline 113 & Bavaria & Kennedy & 0.899 & 0.387 & 0.885 & 0.0252 & 0.00444 & 0.00605 & 0.54 & 0.7 & 0.470 \\
\hline 114 & Modelia & Fontibón & 0.656 & 0.0032 & 0.0174 & 0.0182 & 0.00655 & 0.00125 & 0.64 & 0.7 & 0.268 \\
\hline 115 & Capellania & Fontibón & 1 & 0.423 & 1 & 0.0297 & 0.00788 & 0.00125 & 0.64 & 0.7 & 0.522 \\
\hline 116 & Álamos & Engativá & 1 & 0.353 & 0.949 & 0.0292 & 0.00886 & 0.00045 & 0.66 & 0.8 & 0.515 \\
\hline 117 & Aeropuerto El Dorado & Fontibón & 0.935 & 0.0032 & 0.0128 & 0.031 & 0.00902 & 0.00125 & 0.64 & 0.7 & 0.358 \\
\hline
\end{tabular}


Table VIII. Values of aggravating descriptors for social fragility and lack of resilience factors of Bogota.

\begin{tabular}{|c|c|c|c|c|c|c|c|c|c|c|c|}
\hline Locality & $X_{\mathrm{FS} 1}$ & $X_{\mathrm{FS} 2}$ & $X_{\mathrm{FS} 3}$ & $X_{\mathrm{FS} 4}$ & $X_{\mathrm{FS} 5}$ & $X_{\mathrm{FR} 1}$ & $X_{\mathrm{FR} 2}$ & $X_{\mathrm{FR} 3}$ & $X_{\mathrm{FR} 4}$ & $X_{\mathrm{FR} 5}$ & $X_{\mathrm{FR} 6}$ \\
\hline Antonio Nariño & 0.015 & 398 & 120 & 0.2 & 28338 & 4.871 & 5 & 0.016 & 13 & 2 & 0.0456 \\
\hline Barrios Unidos & 0.002 & 917 & 130 & 0.29 & 25920 & 1.254 & 33 & 0.150 & 9 & 2 & 0.0456 \\
\hline Bosa & 0.249 & 1366 & 92 & 0.51 & 44458 & 0.338 & 3 & 0.038 & 4 & 2 & 0.0702 \\
\hline Chapinero & 0.131 & 612 & 249 & 0 & 9255 & 16.265 & 89 & 0.032 & 19 & 3 & 0.0724 \\
\hline Ciudad Bolívar & 0.239 & 1866 & 78 & 0.92 & 48968 & 0.503 & 3 & 0.035 & 7 & 2 & 0.1884 \\
\hline Engativa & 0.061 & 2747 & 53 & 0.41 & 34958 & 0.183 & 7 & 0.142 & 11 & 2 & 0.1715 \\
\hline Fontibon & 0.129 & 1028 & 34 & 0.39 & 37558 & 0.206 & 4 & 0.109 & 2 & 2 & 0.0456 \\
\hline Kennedy & 0.164 & 2546 & 68 & 0.44 & 41451 & 0.756 & 8 & 0.084 & 1 & 1 & 0.0456 \\
\hline La Candelaria & 0.248 & 100 & 86 & 0.34 & 13074 & 2.509 & 0 & 0.000 & 13 & 1 & 0.0456 \\
\hline Los Mártires & 0.036 & 621 & 84 & 0.33 & 32227 & 2.846 & 103 & 0.033 & 48 & 2 & 0.0596 \\
\hline Puente Aranda & 0.001 & 1323 & 32 & 0.37 & 37211 & 0.616 & 4 & 0.062 & 8 & 2 & 0.1715 \\
\hline Rafael Uribe & 0.237 & 1618 & 109 & 0.5 & 36759 & 1.605 & 11 & 0.084 & 6 & 1 & 0.1715 \\
\hline San Cristobal & 0.265 & 1648 & 55 & 0.82 & 41875 & 3.490 & 19 & 0.108 & 11 & 1 & 0.3383 \\
\hline Santa Fe & 0.771 & 694 & 182 & 0.36 & 17764 & 6.176 & 143 & 0.150 & 46 & 1 & 0.0904 \\
\hline Suba & 0.110 & 2621 & 115 & 0.41 & 25886 & 1.181 & 15 & 0.045 & 4 & 2 & 0.177 \\
\hline Teusaquillo & 0.002 & 681 & 90 & 0.05 & 14437 & 5.556 & 20 & 0.112 & 8 & 3 & 0.1315 \\
\hline Tunjuelito & 0.161 & 941 & 63 & 0.45 & 37702 & 2.540 & 13 & 0.084 & 9 & 1 & 0.0552 \\
\hline Usaquen & 0.050 & 1473 & 74 & 0.33 & 20836 & 3.972 & 28 & 0.129 & 3 & 2 & 0.0456 \\
\hline Usme & 0.168 & 850 & 129 & 1 & 32863 & 0.199 & 2 & 0.021 & 12 & 2 & 0.0456 \\
\hline
\end{tabular}


Table IX. Impact factor, $F$, computed with aggravating factors of social fragility and lack of resilience.

\begin{tabular}{lllllllllllll}
\hline Localidad & $F_{\mathrm{FS} 1}$ & $F_{\mathrm{FS} 2}$ & $F_{\mathrm{FS} 3}$ & $F_{\mathrm{FS} 4}$ & $F_{\mathrm{FS} 5}$ & $F_{\mathrm{FR} 1}$ & $F_{\mathrm{FR} 2}$ & $F_{\mathrm{FR} 3}$ & $F_{\mathrm{FR} 4}$ & $F_{\mathrm{FR} 5}$ & $F_{\mathrm{FR} 6}$ & $F$ \\
\hline Antonio Nariño & 0 & 0.0155 & 0.00538 & 0.2 & 1 & 0.947 & 0.778 & 0.996 & 0 & 0.6 & 0.95 & 0.50 \\
Barrios Unidos & 0 & 0.0964 & 0.00702 & 0.29 & 1 & 0.997 & 0 & 0 & 0 & 0.6 & 0.95 & 0.44 \\
Bosa & 0.162 & 0.222 & 0.00194 & 0.51 & 1 & 1 & 0.92 & 0.92 & 0.367 & 0.6 & 0.93 & 0.61 \\
Chapinero & 0.0268 & 0.0405 & 0.0435 & 0 & 0.125 & 0.419 & 0 & 0.951 & 0 & 0.3 & 0.93 & 0.20 \\
Ciudad Bolívar & 0.146 & 0.423 & 0.00086 & 0.92 & 1 & 0.999 & 0.92 & 0.936 & 0 & 0.6 & 0.81 & 0.67 \\
Engativa & 0.000494 & 0.799 & 0.00000988 & 0.41 & 1 & 1 & 0.564 & 0.00653 & 0 & 0.6 & 0.83 & 0.51 \\
Fontibon & 0.0255 & 0.123 & 0 & 0.39 & 1 & 1 & 0.858 & 0.172 & 0.837 & 0.6 & 0.95 & 0.55 \\
Kennedy & 0.053 & 0.729 & 0.000356 & 0.44 & 1 & 0.99 & 0.436 & 0.444 & 0.959 & 1 & 0.95 & 0.62 \\
La Candelaria & 0.16 & 0.00032 & 0.00142 & 0.34 & 0.373 & 0.986 & 1 & 1 & 0 & 1 & 0.95 & 0.49 \\
Los Mártires & 0 & 0.0418 & 0.00127 & 0.33 & 1 & 0.982 & 0 & 0.946 & 0 & 0.6 & 0.94 & 0.48 \\
Puente Aranda & 0 & 0.208 & 0 & 0.37 & 1 & 0.999 & 0.858 & 0.724 & 0 & 0.6 & 0.83 & 0.52 \\
Rafael Uribe & 0.143 & 0.315 & 0.00382 & 0.5 & 1 & 0.994 & 0.142 & 0.444 & 0.0408 & 1 & 0.83 & 0.56 \\
San Cristobal & 0.189 & 0.327 & 0.0000274 & 0.82 & 1 & 0.973 & 0 & 0.18 & 0 & 1 & 0.66 & 0.59 \\
Santa Fe & 1 & 0.0532 & 0.0191 & 0.36 & 0.763 & 0.915 & 0 & 0 & 0 & 1 & 0.91 & 0.61 \\
Suba & 0.0147 & 0.756 & 0.00464 & 0.41 & 1 & 0.997 & 0 & 0.875 & 0.367 & 0.6 & 0.82 & 0.52 \\
Teusaquillo & 0 & 0.051 & 0.00176 & 0.05 & 0.494 & 0.931 & 0 & 0.147 & 0 & 0.3 & 0.87 & 0.27 \\
Tunjuelito & 0.0503 & 0.102 & 0.000185 & 0.45 & 1 & 0.986 & 0.0356 & 0.444 & 0 & 1 & 0.94 & 0.53 \\
Usaquen & 0 & 0.26 & 0.000632 & 0.33 & 0.921 & 0.965 & 0 & 0.045 & 0.633 & 0.6 & 0.95 & 0.46 \\
Usme & 0.0568 & 0.082 & 0.00685 & 1 & 1 & 1 & 0.964 & 0.988 & 0 & 0.6 & 0.95 & 0.67 \\
\hline
\end{tabular}


Table X. Seismic risk of Bogota.

\begin{tabular}{llll}
\hline Locality & $R_{\mathrm{F}}$ & $F$ & $R_{\mathrm{T}}$ \\
\hline Antonio Nariño & 0.41 & 0.50 & 0.62 \\
Barrios Unidos & 0.27 & 0.44 & 0.38 \\
Bosa & 0.18 & 0.61 & 0.28 \\
Chapinero & 0.47 & 0.20 & 0.57 \\
Ciudad Bolívar & 0.39 & 0.75 & 0.65 \\
Engativa & 0.36 & 0.51 & 0.54 \\
Fontibon & 0.41 & 0.55 & 0.64 \\
Kennedy & 0.24 & 0.62 & 0.38 \\
La Candelaria & 0.62 & 0.49 & 0.93 \\
Los Mártires & 0.47 & 0.48 & 0.69 \\
Puente Aranda & 0.43 & 0.52 & 0.65 \\
Rafael Uribe & 0.39 & 0.56 & 0.61 \\
San Cristobal & 0.37 & 0.59 & 0.58 \\
Santa Fe & 0.48 & 0.61 & 0.77 \\
Suba & 0.25 & 0.52 & 0.38 \\
Teusaquillo & 0.40 & 0.27 & 0.51 \\
Tunjuelito & 0.39 & 0.53 & 0.60 \\
Usaquen & 0.30 & 0.46 & 0.44 \\
Usme & 0.37 & 0.67 & 0.62 \\
Bogota & 0.32 & 0.55 & 0.50 \\
\hline
\end{tabular}

total seismic risk, because its impact factor is significant, although it is not the highest of the city. The localities with greater impact factor are Usme, Ciudad Bolivar, Ciudad Kennedy and Bosa, whereas the lowest values are those of Barrios Unidos, Teusaquillo and Chapinero. High values of the greater physical risk index, in addition to Candelaria, are the localities of Santa Fe, Chapinero and Los Martires, whereas the physical risk index is less in Ciudad Kennedy and Bosa. The greater values of total risk index appear in the localities of Candelaria, Santafé and Los Martires, and the smaller values are those of Ciudad Kennedy, Barrios Unidos and Bosa.

Bogota was previously studied using the earlier model. Figure 13 shows the obtained results (Cardona, 2001). This was the first integrated analysis of the seismic risk of the city. The results obtained with that model only allow ordering the localities in function of their relative total risk. Although the index values are different, the ranking using both models is similar. For example, the locality of Tunjuelito has the smallest total risk and the locality of Candelaria has the greatest total risk with the proposed alternative model and it is the second with the previous 


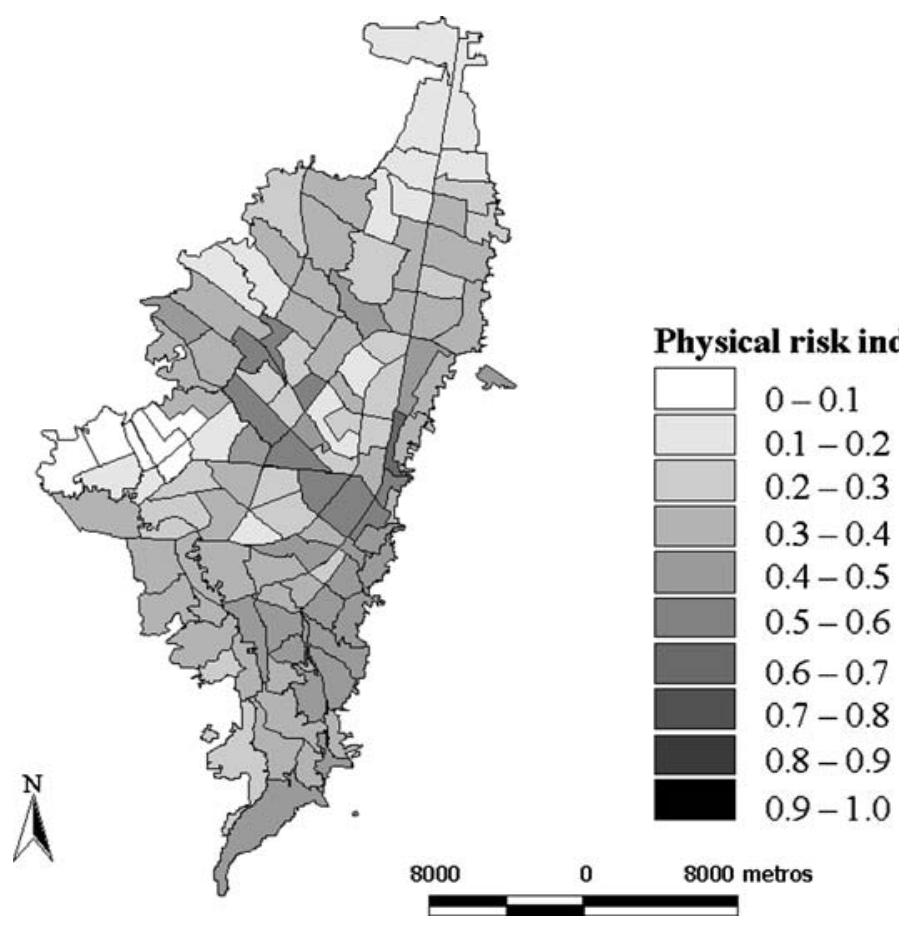

Figure 8. Physical risk index, $R_{F}$, for the UPZ of Bogota.

one. The other localities maintain a similar order of the Figures 12 and 13.

\subsection{SEISMIC RISK OF BARCELONA}

The city of Barcelona, Spain, is subdivided in ten districts (see Figure 14), which are directed by a Mayor. The districts have management competences in subjects like urbanism, public space, infrastructure maintenance, etc. They are: Ciutat Vella, Eixample, Sants-Montjuïc, Les Corts, Sarrià-Sant Gervasi, Gràcia, Horta-Guinardó, Nou Barris, Sant Andreu and Sant Martí. The districts are subdivided in 38 neighbourhoods or large statistical zones. Barcelona is also subdivided in 248 small statistical zones (ZRP). The physical risk index was calculated from a probabilistic risk scenario developed in the framework of the Risk-UE project (ICC/CIMNE, 2004). Figure 15 shows the physical risk scenario, calculated considering the 248 small ZRP zones. The impact factor was calculated by district, due to the availability of data at this level only.

Table XI shows examples of the physical risk descriptors for some of the 248 ZRP. Table XII presents examples of the physical risk factors. 


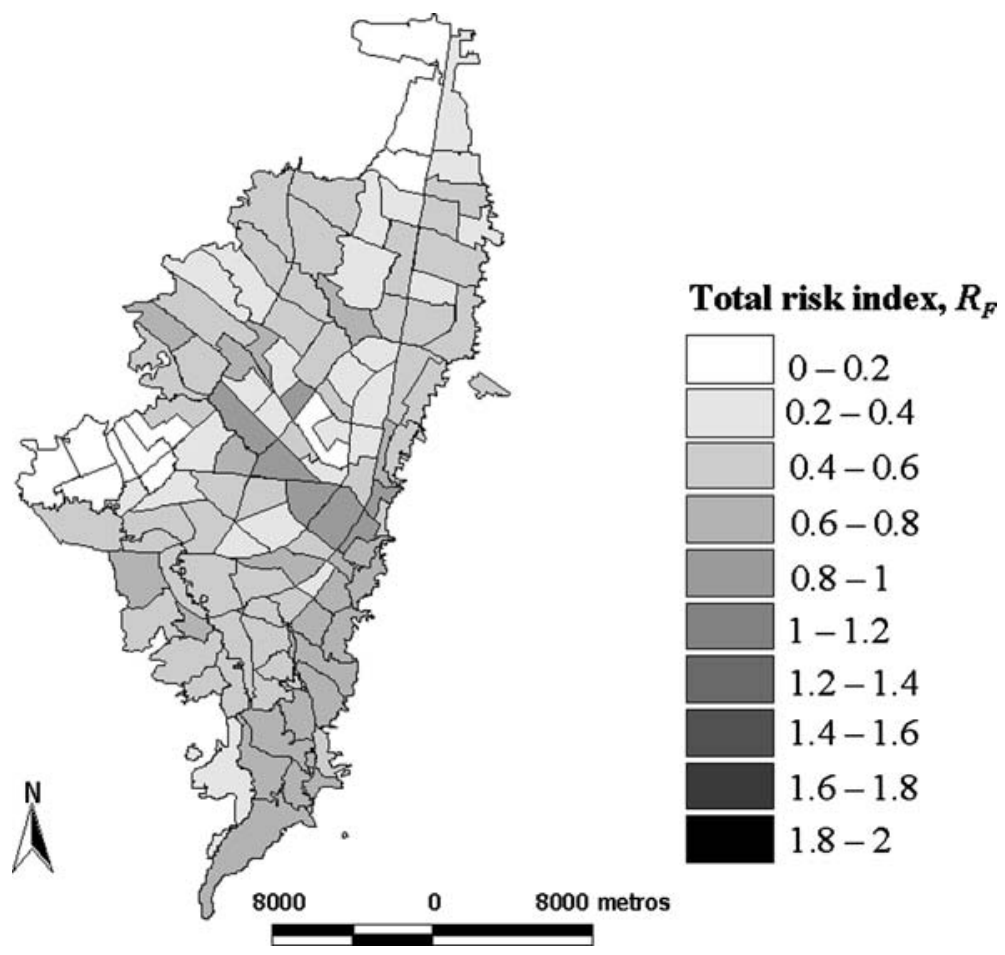

Figure 9. Total risk index, $R_{T}$, for the UPZ of Bogota.

Physical risk index, $R_{F}$

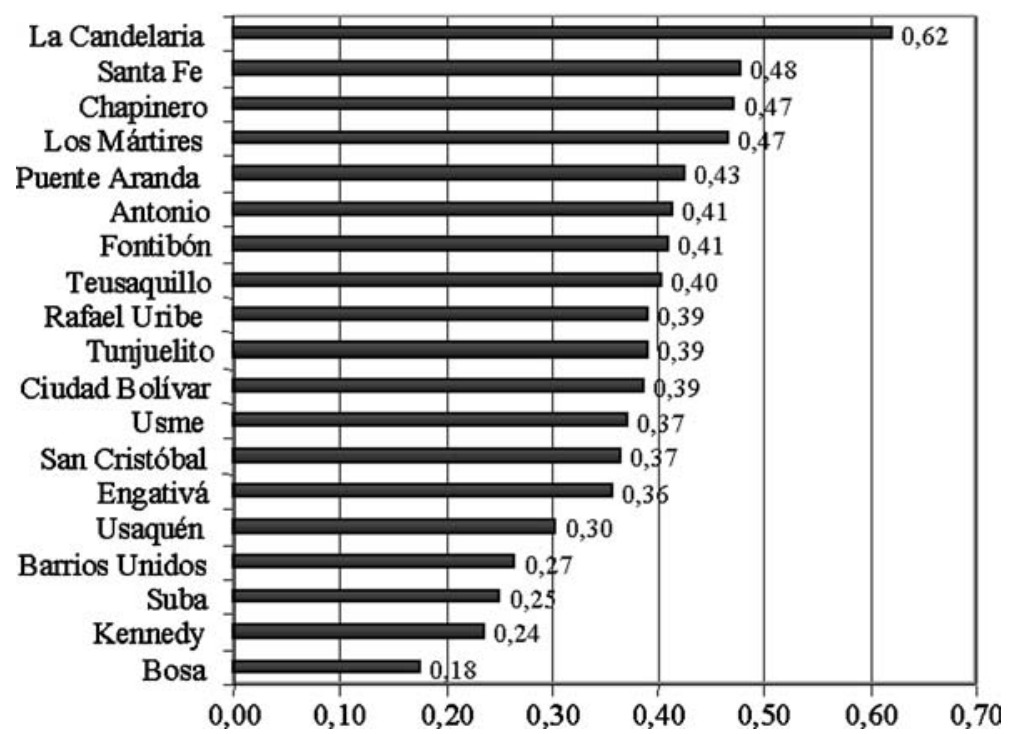

Figure 10. Physical risk index for the localities of Bogota, in descendent order. 


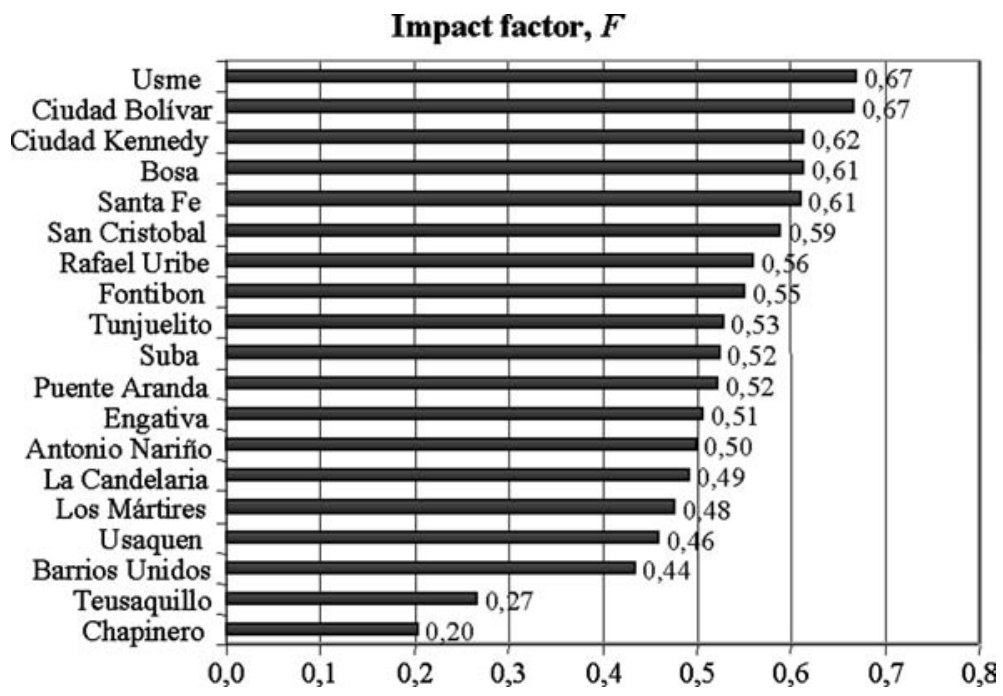

Figure 11. Impact factor for the localities of Bogota, in descendent order.

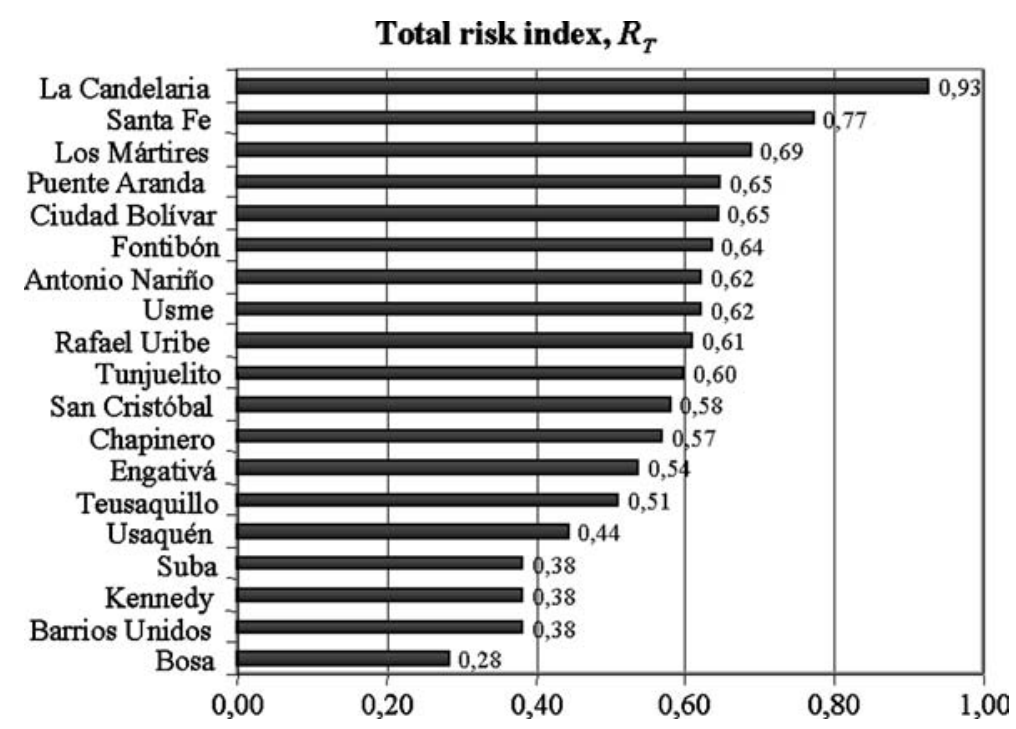

Figure 12. Total risk index for the localities of Bogota, in descendent order.

Table XIII shows the values for descriptors of social fragility and lack of resilience, and Table XIV displays the aggravating factors obtained by applying the transformation functions (Figures 2-4). In addition, 
Total risk, $I_{R T}$

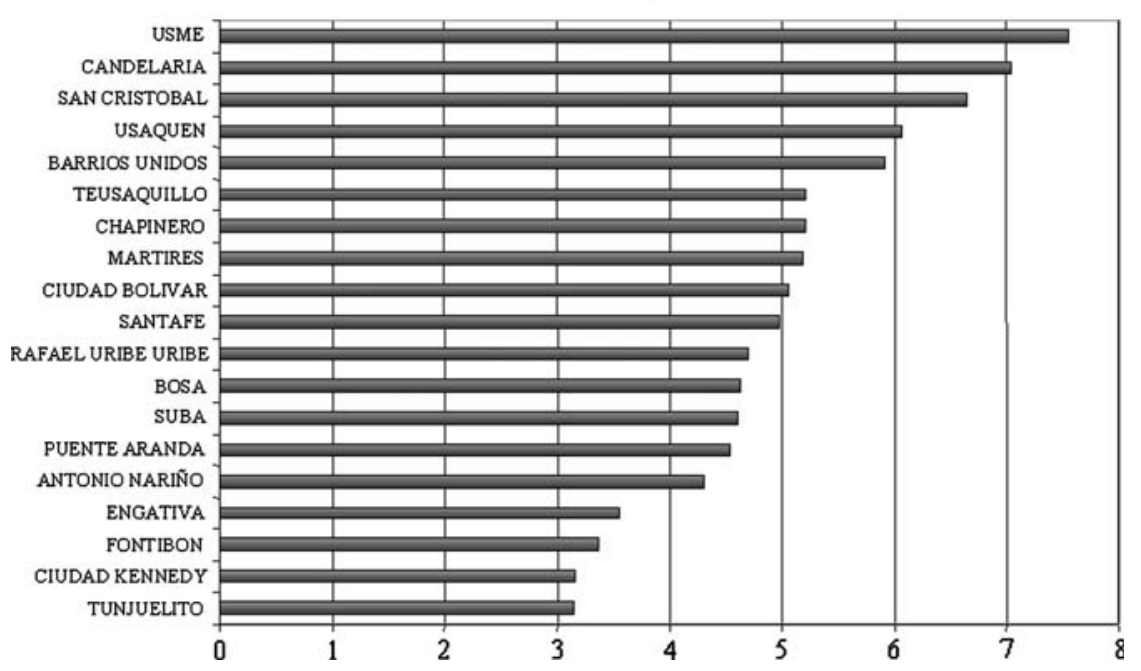

Figure 13. Total risk index for the localities of Bogota, obtained with the Cardona's model.

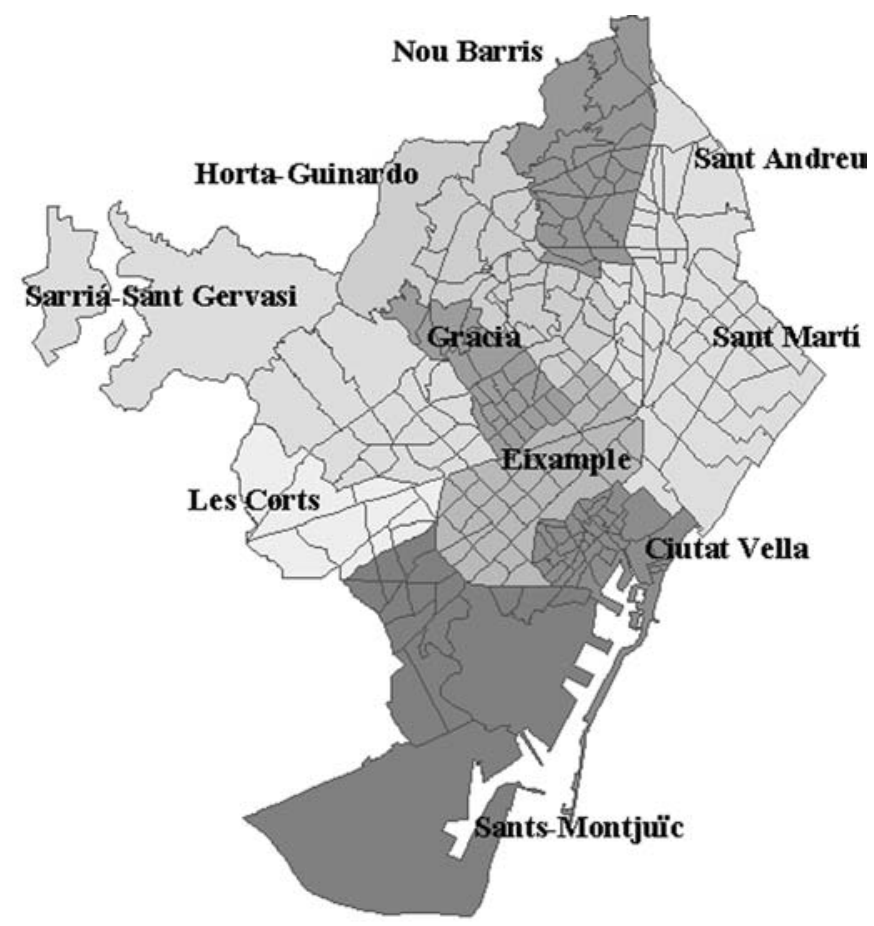

5

5 kilometers

Figure 14. Territorial division of Barcelona. 


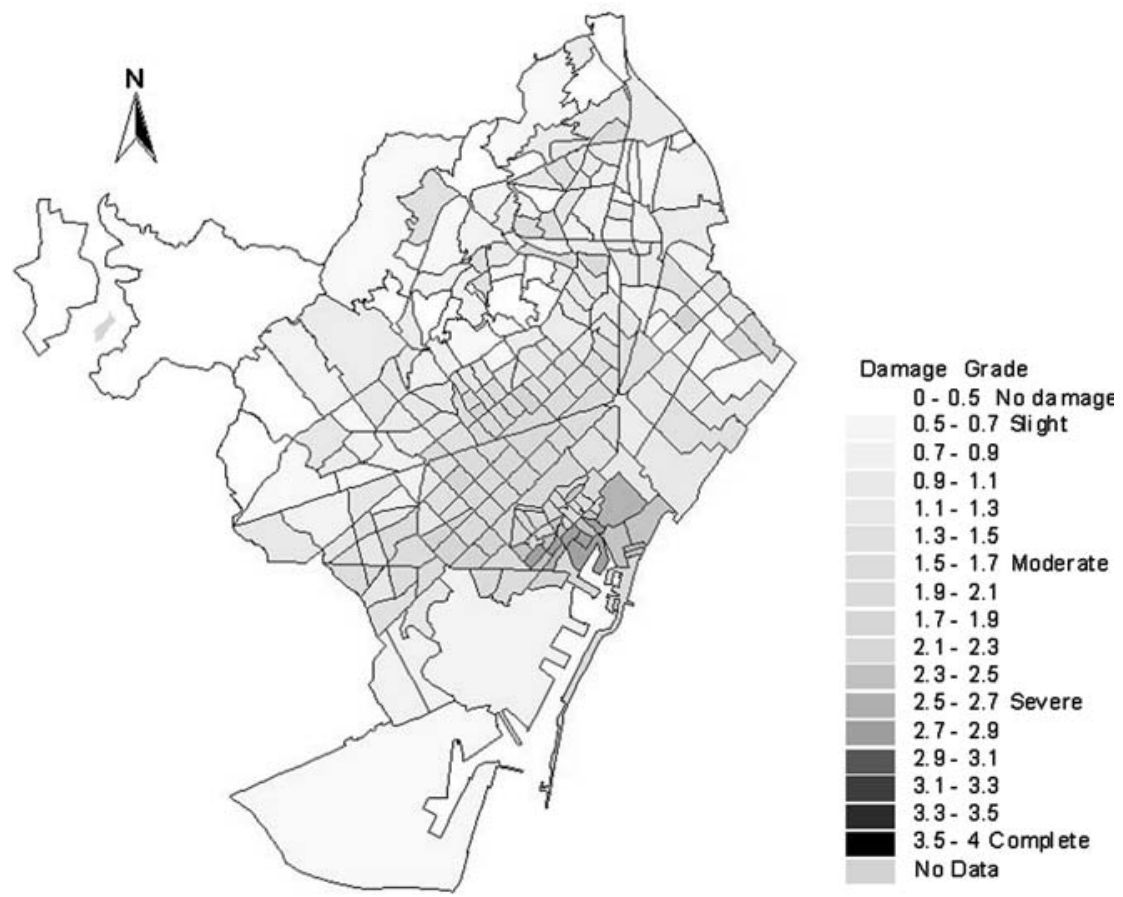

Figure 15. Physical risk scenario for Barcelona, using 248 small statistical zones (ZRP).

Table XIV, at the bottom, shows the average values of the factors for the city, normalised using the density of population. Table XV presents some examples of the final results of the physical risk index, the impact factor and total risk index for each ZRP zone. The weights are the same as those used in Bogota (Tables IV and V). Figures 16-18 show the results for the physical risk index, the impact factor and the total risk index for Barcelona using the model proposed above.

\subsection{COMPARISON AND DISCUSSION OF THE RESULTS}

The results obtained for Bogota have been compared with those obtained for Barcelona. Table XVI shows the average risk values for both cities. Bogota is located in a zone with intermediate seismic hazard, whereas Barcelona is located in a zone with low to moderate seismic hazard. The average values obtained for the physical risk index, $R_{\mathrm{F}}$, clearly reflect this situation. It is interesting to remark that the results obtained for the impact factor, $F$, are not so different for both cities. The lowest values of this impact factor are similar ( 0.20 for the locality of Chapinero in Bogota and 0.18 for the district of Sarrià in Barcelona). The difference between the 
Table XI. Examples of descriptor values of physical risk.

\begin{tabular}{lrrrllllll}
\hline ZRP & $X_{\mathrm{RF} 1}$ & $X_{\mathrm{RF} 2}$ & $X_{\mathrm{RF} 3}$ & $X_{\mathrm{RF} 4}$ & $X_{\mathrm{RF} 5}$ & $X_{\mathrm{RF} 6}$ & $X_{\mathrm{RF} 7}$ & $X_{\mathrm{RF} 8}$ & $X_{\mathrm{RF} 9}$ \\
\hline 001 & 16.9 & 6 & 12 & 0.02 & 0.02 & 0.02 & 0.17 & 0.32 & 0.025 \\
002 & 19.5 & 10 & 21 & 0.02 & 0.02 & 0.02 & 0.17 & 0.32 & 0 \\
003 & 19.7 & 9 & 19 & 0.02 & 0.02 & 0.02 & 0.17 & 0.32 & 0 \\
004 & 20.5 & 6 & 12 & 0.02 & 0.02 & 0.02 & 0.17 & 0.32 & 0.2 \\
005 & 20.7 & 7 & 15 & 0.02 & 0.02 & 0.02 & 0.17 & 0.32 & 0.2 \\
006 & 22.2 & 5 & 11 & 0.02 & 0.02 & 0.02 & 0.17 & 0.32 & 0 \\
007 & 24.2 & 7 & 14 & 0.02 & 0.02 & 0.02 & 0.17 & 0.32 & 0.2 \\
008 & 10.1 & 3 & 6 & 0.02 & 0.02 & 0.02 & 0.17 & 0.32 & 0 \\
009 & 8.9 & 2 & 5 & 0.02 & 0.02 & 0.02 & 0.17 & 0.32 & 0 \\
010 & 8.3 & 4 & 8 & 0.02 & 0.02 & 0.02 & 0.17 & 0.32 & 0 \\
$\ldots$ & $\ldots$ & $\ldots$ & $\ldots$ & $\ldots$ & $\ldots$ & $\ldots$ & $\ldots$ & $\ldots$ & $\ldots$ \\
240 & 3.9 & 3 & 6 & 0.02 & 0.02 & 0.02 & 0.17 & 0.32 & 0.05 \\
241 & 1.6 & 4 & 8 & 0.02 & 0.02 & 0.02 & 0.17 & 0.32 & 0 \\
242 & 2.4 & 5 & 10 & 0.02 & 0.02 & 0.02 & 0.17 & 0.32 & 0.025 \\
243 & 11.1 & 19 & 40 & 0.02 & 0.02 & 0.02 & 0.17 & 0.32 & 0.025 \\
244 & 2.9 & 7 & 15 & 0.02 & 0.02 & 0.02 & 0.17 & 0.32 & 0 \\
245 & 8.4 & 16 & 34 & 0.02 & 0.02 & 0.02 & 0.17 & 0.32 & 0 \\
246 & 3.3 & 7 & 15 & 0.02 & 0.02 & 0.02 & 0.17 & 0.32 & 0.025 \\
247 & 3.3 & 8 & 18 & 0.02 & 0.02 & 0.02 & 0.17 & 0.32 & 0.025 \\
248 & 4.9 & 9 & 20 & 0.02 & 0.02 & 0.02 & 0.17 & 0.32 & 0 \\
\hline & & & & & & & & &
\end{tabular}

highest values in the two cities is more noticeable ( 0.67 for the locality of Usme in Bogota and 0.71 for the district of Sant Marti in Barcelona). Although the highest value for Barcelona is larger than the highest value of Bogotá, the average value for Barcelona is smaller than the value for Bogotá. This is the aspect which shows the big difference between the cities regarding the holistic seismic risk. The proposed methodology, which permits a unified holistic evaluation of risk, allows performing in the future comparisons among other different cities worldwide.

\section{Conclusions}

Risk estimation requires a multidisciplinary approach that takes into account not only the expected physical damage, the number and type of casualties or economic losses, but also other social, organizational and institutional issues related to the development of communities that contribute to the creation of risk. At the urban level, for example, vulnerability 
Table XII. Factors and physical risk index, $R_{F}$, for Barcelona.

\begin{tabular}{|c|c|c|c|c|c|c|c|c|c|c|}
\hline ZRP & $F_{\mathrm{RF} 1}$ & $F_{\mathrm{RF} 2}$ & $F_{\mathrm{RF} 3}$ & $F_{\mathrm{RF} 4}$ & $F_{\mathrm{RF} 5}$ & $F_{\mathrm{RF} 6}$ & $F_{\mathrm{RF} 7}$ & $F_{\mathrm{RF} 8}$ & $F_{\mathrm{RF} 9}$ & $R_{\mathrm{F}}$ \\
\hline 001 & 0.952 & 0.0288 & 0.0512 & 0.02 & 0.02 & 0.02 & 0.17 & 0.32 & 0.025 & 0.306 \\
\hline 002 & 0.999 & 0.08 & 0.157 & 0.02 & 0.02 & 0.02 & 0.17 & 0.32 & 0 & 0.331 \\
\hline 003 & 1 & 0.0648 & 0.128 & 0.02 & 0.02 & 0.02 & 0.17 & 0.32 & 0 & 0.328 \\
\hline 004 & 1 & 0.0288 & 0.0512 & 0.02 & 0.02 & 0.02 & 0.17 & 0.32 & 0.2 & 0.336 \\
\hline 005 & 1 & 0.0392 & 0.08 & 0.02 & 0.02 & 0.02 & 0.17 & 0.32 & 0.2 & 0.340 \\
\hline 006 & 1 & 0.02 & 0.043 & 0.02 & 0.02 & 0.02 & 0.17 & 0.32 & 0 & 0.316 \\
\hline 007 & 1 & 0.0392 & 0.0697 & 0.02 & 0.02 & 0.02 & 0.17 & 0.32 & 0.2 & 0.339 \\
\hline 008 & 0.51 & 0.0072 & 0.0128 & 0.02 & 0.02 & 0.02 & 0.17 & 0.32 & 0 & 0.172 \\
\hline 009 & 0.396 & 0.0032 & 0.00889 & 0.02 & 0.02 & 0.02 & 0.17 & 0.32 & 0 & 0.139 \\
\hline 010 & 0.344 & 0.0128 & 0.0228 & 0.02 & 0.02 & 0.02 & 0.17 & 0.32 & 0 & 0.126 \\
\hline$\cdots$ & $\ldots$ & $\ldots$ & $\ldots$ & $\ldots$ & $\ldots$ & $\ldots$ & $\ldots$ & $\ldots$ & $\ldots$ & $\ldots$ \\
\hline 240 & 0.0761 & 0.0072 & 0.0128 & 0.02 & 0.02 & 0.02 & 0.17 & 0.32 & 0.05 & 0.053 \\
\hline 241 & 0.0128 & 0.0128 & 0.0228 & 0.02 & 0.02 & 0.02 & 0.17 & 0.32 & 0 & 0.032 \\
\hline 242 & 0.0288 & 0.02 & 0.0356 & 0.02 & 0.02 & 0.02 & 0.17 & 0.32 & 0.025 & 0.041 \\
\hline 243 & 0.604 & 0.289 & 0.564 & 0.02 & 0.02 & 0.02 & 0.17 & 0.32 & 0.025 & 0.279 \\
\hline 244 & 0.042 & 0.0392 & 0.08 & 0.02 & 0.02 & 0.02 & 0.17 & 0.32 & 0 & 0.048 \\
\hline 245 & 0.353 & 0.205 & 0.411 & 0.02 & 0.02 & 0.02 & 0.17 & 0.32 & 0 & 0.183 \\
\hline 246 & 0.0544 & 0.0392 & 0.08 & 0.02 & 0.02 & 0.02 & 0.17 & 0.32 & 0.025 & 0.054 \\
\hline 247 & 0.0544 & 0.0512 & 0.115 & 0.02 & 0.02 & 0.02 & 0.17 & 0.32 & 0.025 & 0.058 \\
\hline 248 & 0.12 & 0.0648 & 0.142 & 0.02 & 0.02 & 0.02 & 0.17 & 0.32 & 0 & 0.078 \\
\hline Barcelona & 0.152 & 0.017 & 0.033 & 0.020 & 0.020 & 0.020 & 0.170 & 0.320 & 0.031 & 0.076 \\
\hline
\end{tabular}

Table XIII. Values for the aggravating descriptors for social fragility and lack of resilience factors of Barcelona.

\begin{tabular}{llrrrrrrrrrrl}
\hline District & $X_{\mathrm{FS} 1}$ & $X_{\mathrm{FS} 2}$ & $X_{\mathrm{FS} 3}$ & $X_{\mathrm{FS} 4}$ & $X_{\mathrm{FS} 5}$ & $X_{\mathrm{FR} 1}$ & $X_{\mathrm{FR} 2}$ & $X_{\mathrm{FR} 3}$ & $X_{\mathrm{FR} 4}$ & $X_{\mathrm{FR} 5}$ & $X_{\mathrm{FR} 6}$ \\
\hline Ciutat Vella & 0.2 & 119 & 252.87 & 0.8 & 12690 & 4.9650 & 11 & 0.0828 & 15 & 1 & 1 \\
Eixample & 0 & 119 & 60.04 & 0.3 & 14186 & 6.1475 & 14 & 0.0180 & 18 & 4 & 1 \\
Sant-Montjuic & 0 & 102 & 73.61 & 0.3 & 6834 & 0 & 0 & 0.1219 & 15 & 3 & 1 \\
Les Corts & 0 & 81 & 30.99 & 0.1 & 14080 & 10.6864 & 24 & 0.0424 & 18 & 4 & 1 \\
Sarrià-Sant & 0 & 95 & 30.99 & 0 & 11647 & 10.8704 & 24 & 0.0194 & 8 & 4 & 1 \\
Gervasi & & & & & & & & & & & \\
Gràcia & 0 & 115 & 42.66 & 0.2 & 16570 & 7.1269 & 16 & 0.0324 & 8 & 4 & 1 \\
Horta- & 0.1 & 95 & 36.00 & 0.5 & 21573 & 16.1716 & 36 & 0.0369 & 8 & 2 & 1 \\
$\quad$ Guinardó & & & & & & & & & & & \\
Nou Barris & 0.1 & 95 & 31.54 & 0.8 & 28256 & 0 & 0 & 0.0430 & 10 & 1 & 1 \\
Sant Andreu & 0.1 & 91 & 31.54 & 0.5 & 19890 & 1.1325 & 3 & 0.0198 & 10 & 2 & 1 \\
Sant Martí & 0.3 & 93 & 42.44 & 0.8 & 19069 & 0 & 0 & 0.0337 & 3 & 1 & 1 \\
\hline
\end{tabular}


Table XIV. Impact factor, $F$, computed with aggravating factors of social fragility, $F_{\mathrm{FS}}$, and lack of resilience, $F_{\mathrm{FR}}$ for Barcelona.

\begin{tabular}{|c|c|c|c|c|c|c|c|c|c|c|c|}
\hline District & $F_{\mathrm{FS} 1}$ & $F_{\mathrm{FS} 2}$ & $F_{\mathrm{FS} 3}$ & $F_{\mathrm{FS} 4}$ & $F_{\mathrm{FS} 5}$ & $F_{\mathrm{FR} 1}$ & $F_{\mathrm{FR} 2}$ & $F_{\mathrm{FR} 3}$ & $F_{\mathrm{FR} 4}$ & $F_{\mathrm{FR} 5}$ & $F$ \\
\hline Ciutat Vella & 0.0918 & 0.00061 & 0.0452 & 0.8 & 0.342 & 0.964 & 0.142 & 0.461 & 0 & 0.5 & 0.4437 \\
\hline Eixample & 0 & 0.00061 & 0.000111 & 0.3 & 0.471 & 0.925 & 0.00889 & 0.993 & 0 & 0.5 & 0.2796 \\
\hline Sant-Montjuic & 0 & 0.000347 & 0.000612 & 0.3 & 0.0364 & 1 & 1 & 0.0806 & 0 & 0.5 & 0.2558 \\
\hline Les Corts & 0 & 0.000123 & 0 & 0.1 & 0.461 & 0.755 & 0 & 0.893 & 0 & 0.5 & 0.2270 \\
\hline Sarrià-Sant Gervasi & 0 & 0.00026 & 0 & 0 & 0.265 & 0.769 & 0 & 0.991 & 0 & 0.5 & 0.1785 \\
\hline Gràcia & 0 & 0.000542 & 0 & 0.2 & 0.678 & 0.894 & 0 & 0.949 & 0 & 0.5 & 0.2947 \\
\hline Horta-Guinardó & 0.0102 & 0.00026 & 0 & 0.5 & 0.947 & 0.436 & 0 & 0 & 0 & 0.5 & 0.3875 \\
\hline Nou Barris & 0.0102 & 0.00026 & 0 & 0.8 & 1 & 1 & 1 & 0.889 & 0 & 0.5 & 0.6164 \\
\hline Sant Andreu & 0.0102 & 0.000215 & 0 & 0.5 & 0.882 & 0.997 & 0.92 & 0.99 & 0 & 0.5 & 0.5042 \\
\hline Sant Martí & 0.255 & 0.000237 & 0 & 0.8 & 0.84 & 1 & 1 & 0.943 & 0.633 & 0.5 & 0.6591 \\
\hline Barcelona & 0.04 & 0.00033 & 0.00352 & 0.48 & 0.69 & 0.87 & 0.45 & 0.75 & 0.54 & 0.5 & 0.42 \\
\hline
\end{tabular}


Table $X V$. Seismic risk of Barcelona.

\begin{tabular}{|c|c|c|c|}
\hline ZRP & $R_{F}$ & $F$ & $R_{T}$ \\
\hline 001 & 0.306 & 0.444 & 0.442 \\
\hline 002 & 0.331 & 0.444 & 0.479 \\
\hline 003 & 0.328 & 0.444 & 0.473 \\
\hline 004 & 0.336 & 0.444 & 0.485 \\
\hline 005 & 0.340 & 0.444 & 0.491 \\
\hline 006 & 0.316 & 0.444 & 0.456 \\
\hline 007 & 0.339 & 0.444 & 0.489 \\
\hline 008 & 0.172 & 0.444 & 0.248 \\
\hline 009 & 0.139 & 0.444 & 0.200 \\
\hline 010 & 0.126 & 0.444 & 0.182 \\
\hline$\ldots$ & $\ldots$ & $\ldots$ & $\ldots$ \\
\hline 240 & 0.053 & 0.659 & 0.088 \\
\hline 241 & 0.032 & 0.659 & 0.053 \\
\hline 242 & 0.041 & 0.659 & 0.068 \\
\hline 243 & 0.279 & 0.659 & 0.462 \\
\hline 244 & 0.048 & 0.659 & 0.080 \\
\hline 245 & 0.183 & 0.659 & 0.303 \\
\hline 246 & 0.054 & 0.659 & 0.089 \\
\hline 247 & 0.058 & 0.659 & 0.097 \\
\hline 248 & 0.078 & 0.659 & 0.130 \\
\hline Barcelona & 0.0759 & 0.42 & 0.1102 \\
\hline
\end{tabular}

seen as an internal risk factor should be related not only to the level of exposure or the physical susceptibility of the buildings and infrastructure material elements potentially affected, but also to the social fragility and the lack of resilience of the exposed community. The absence of institutional and community organization, weak preparedness for emergency response, political instability and the lack of economic health in a geographical area contribute to risk increasing. Therefore, the potential negative consequences are not only related to the effects of the hazardous event as such, but also to the capacity to absorb the effects and the control of its implications in a given geographical area.

For the modelling, a simplified but multidisciplinary representation of urban seismic risk has been suggested, based on the parametric use of variables that reflect aspects of such risk. This parametric approach is not more than a model formulated in the most realistic possible manner, to which corrections or alternative figures may be continuously introduced. The consideration of physical aspects allowed the construc- 


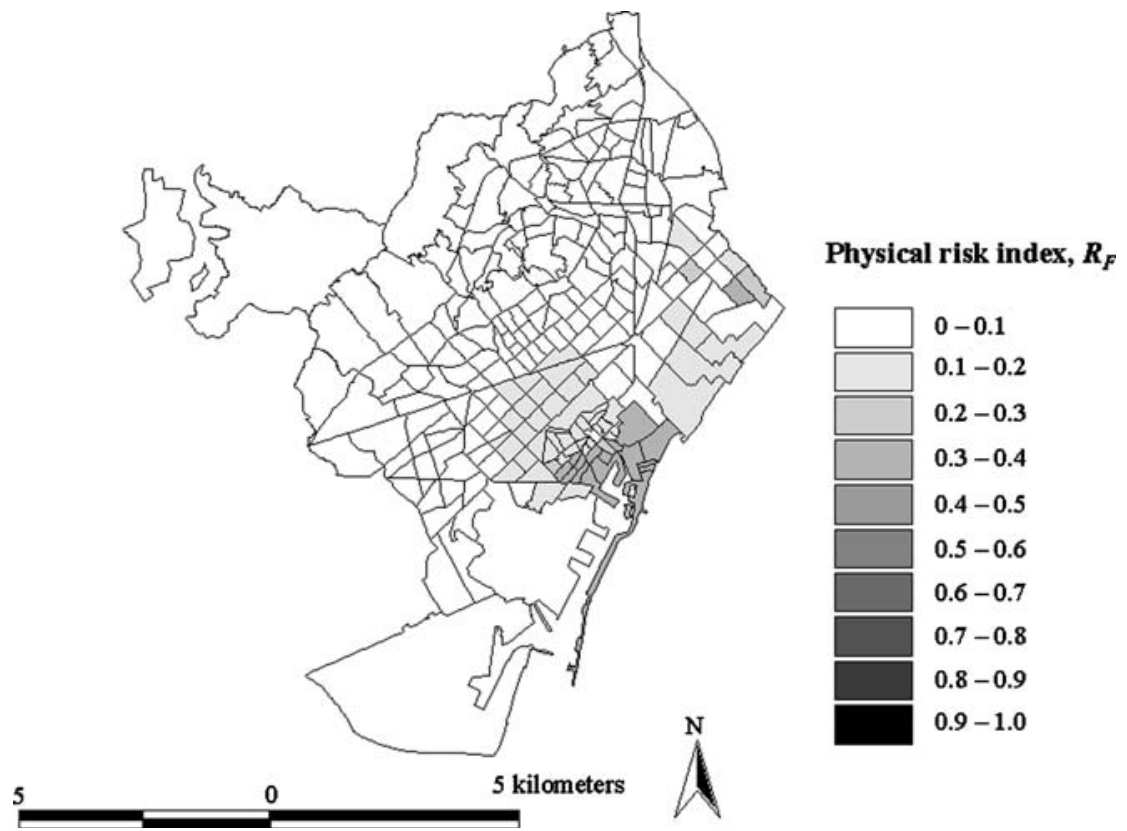

Figure 16. Physical risk index for Barcelona, using 248 small statistical zones (ZRP).

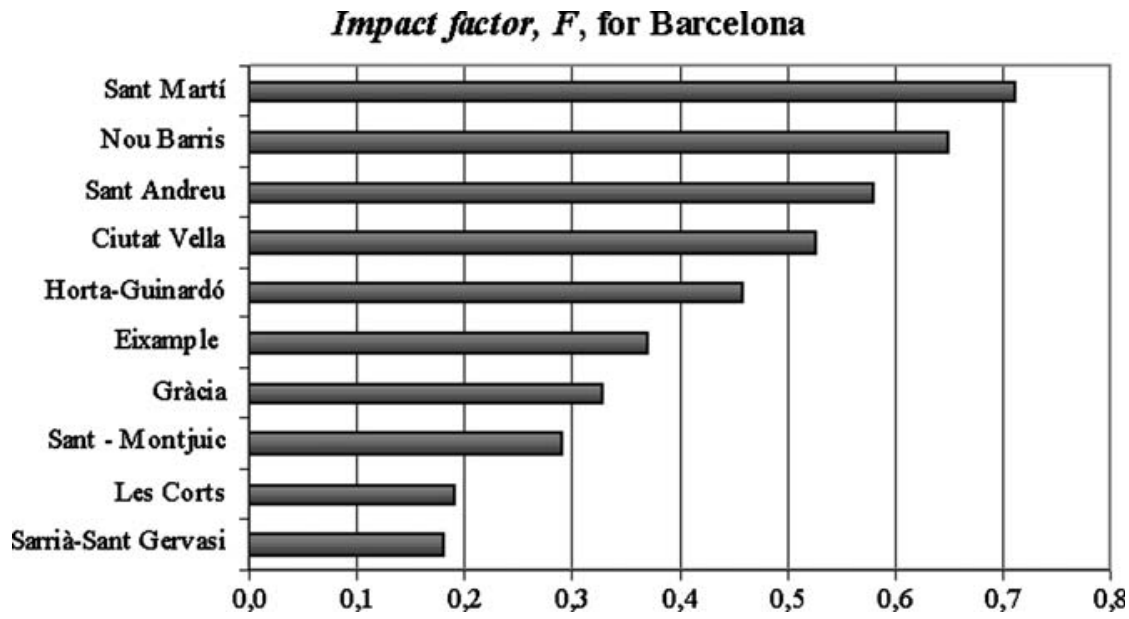

Figure 17. Impact factor for the districts of Barcelona.

tion of a physical risk index. Also, the contextual variables (social, economic, etc.) allowed the construction of an impact factor. The former is built from the information about the seismic scenarios of physical dam- 


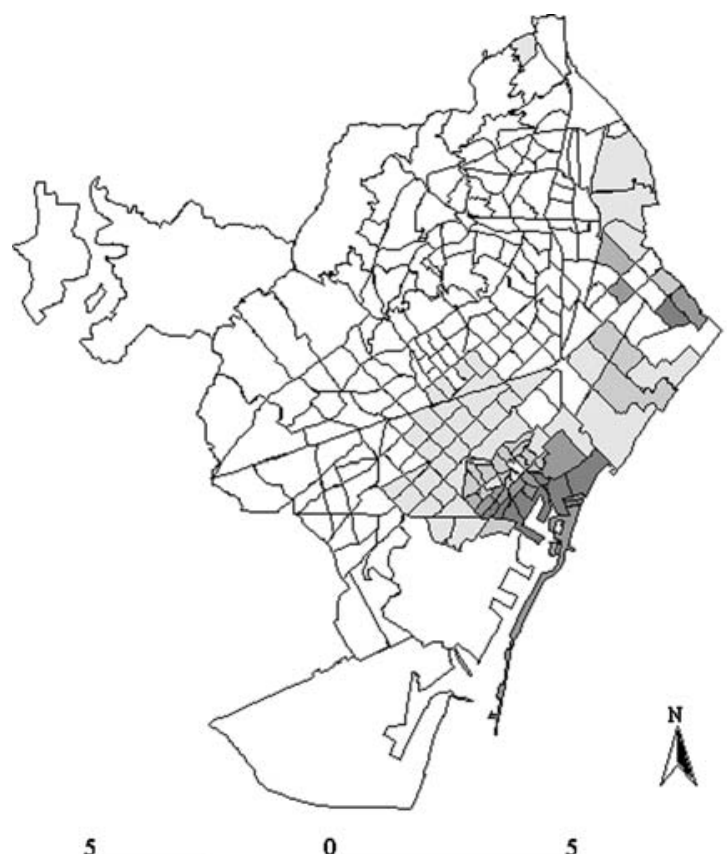

Total risk index, $R_{T}$

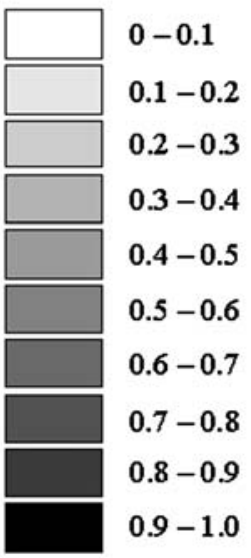

10 Kilometres

Figure 18. Total risk index for Barcelona, using the 248 small statistical zones (ZRP).

Table XVI. Comparison of the mean values between Bogota and Barcelona.

\begin{tabular}{lll}
\hline Index & Bogota & Barcelona \\
\hline Physical risk, $R_{F}$ & 0.225 & 0.0759 \\
Impact factor, $F$ & 0.663 & 0.42 \\
Total risk, $R_{T}$ & 0.374 & 0.1102 \\
\hline
\end{tabular}

age (direct effects) and the latter is the result from the estimation of aggravating conditions (indirect effects) based on descriptors and factors related to the social fragility and the lack of resilience of the exposed elements.

This new model for holistic evaluation of risk facilitates the integrated risk management by the different stakeholders involved in risk reduction decision-making. It permits the follow-up of the risk situation and the effectiveness of the prevention and mitigation measures can be easily achieved. Results can be verified and the mitigation priorities can be 
established as regards the prevention and planning actions to modify those conditions having a greater influence on risk in the city. Once the results have been expressed in graphs for each locality or district, it is easy to identify the most relevant aspects of the total risk index, with no need for further analysis and interpretation of results. Finally, this method allows to compare risk among different cities around the world and to perform a multi-hazard risk analysis.

\section{Acknowledgements}

The authors express gratitude to the Inter-American Development Bank (IDB) for the financial support through the Information and Indicators Program for Disaster Risk Management for Latin America and the Caribbean (ATN/JF-7907-RG Operation) and to the Ministry of Education and Science of Spain, project "Development and application of advanced procedures for the evaluation of the seismic vulnerability and risk of structures" (in Spanish) - EVASIS - (REN2002-03365/RIES).

\section{Appendix: Calculation of the Weighting Factors}

The Hierarchic Analytical Process - AHP is a technique used for the decision making with multiple attributes (Saaty, 1987, 2001; Saaty and Vargas, 1991). It allows the decomposition of a problem into a hierarchy and this assures that the qualitative and quantitative aspects of the problem are incorporated in the evaluation process, during which the opinion is extracted systematically by means of pair-wise comparisons. AHP allows the application of data, experience, knowledge, and intuition of a logical and deep form.

AHP is a compensatory decision methodology because alternatives that are efficient with respect to one or more objectives can compensate by their performance with respect to other objectives. AHP allows for the application of data, experience, insights, and intuition in a logical and thorough way within a hierarchy as a whole. In particular, AHP as weighting method enables decision-maker to derive weights as opposed to arbitrarily assign them (JRC-EC, 2002, 2003).

The core of AHP is an ordinal pair-wise comparison of attributes, subindicators in this context, in which preference statements are addressed. The strength of preference is expressed on a semantic scale of 1-9, which keeps measurement within the same order of magnitude. A preference of 1 indicates equality between two sub-indicators while a preference of 9 indicates that one sub-indicator is 9 times larger or more important than the one to which it is being compared. These comparisons provide the matrix 
of Table A.1, in which, for example, the factor $F_{\mathrm{RF} 7}$ is five times more important than the factor $F_{\mathrm{RF} 1}$.

The relative weights of the sub-indicators are calculated using an eigenvector technique. One of the advantages of this method is that it allows checking the consistency of the comparison matrix through the calculation of its eigenvalues and of a consistency index.

AHP tolerates inconsistency through the amount of redundancy. For a matrix of size $n \times n$, only $n-1$ comparisons are required to establish weights for $n$ indicators. The actual number of comparisons performed in AHP is $n \times(n-1) / 2$. This redundancy is a useful feature as it is analogous to estimating a number by calculating the average of repeated observations. This results in a set of weights that are less sensitive to errors of judgment. In addition, this redundancy allows for a measure of these judgment errors by providing a means of calculating a consistency ratio CR (Saaty, 1987; Karlsson, 1998)

$$
\mathrm{CR}=\frac{\mathrm{CI}}{\mathrm{CI}_{\text {random }}}
$$

obtained as a relation between a consistency index

$$
\mathrm{CI}=\frac{\lambda_{\max }-n}{n-1}
$$

and the value of the same consistency index $\mathrm{CI}_{\text {random }}$ obtained for a comparison matrix randomly generated, were $\lambda_{\max }$ is the principal eigenvalue of the pair wise comparison matrix. According to Saaty, a good precision is assured for small consistency ratios (CR less than 0.1 are suggested as a rule-of-thumb, although even 0.2 is often cited). If this condition is not

Table A.1. Matrix of comparisons for physical risk.

\begin{tabular}{lllllllll}
\hline & $F_{\mathrm{RF} 1}$ & $F_{\mathrm{RF} 2}$ & $F_{\mathrm{RF} 3}$ & $F_{\mathrm{RF} 4}$ & $F_{\mathrm{RF} 5}$ & $F_{\mathrm{RF} 6}$ & $F_{\mathrm{RF} 7}$ & $F_{\mathrm{RF} 8}$ \\
\hline$F_{\mathrm{RF} 1}$ & 1 & 4 & 4 & 2 & 3 & 3 & 5 & 5 \\
$F_{\mathrm{RF} 2}$ & 0.25 & 1 & 1 & 0.5 & 1 & 1 & 3 & 3 \\
$F_{\mathrm{RF} 3}$ & 0.25 & 1 & 1 & 0.5 & 1 & 1 & 3 & 3 \\
$F_{\mathrm{RF} 4}$ & 0.50 & 2 & 2 & 1 & 2 & 2 & 4 & 4 \\
$F_{\mathrm{RF} 5}$ & 0.33 & 1 & 1 & 0.5 & 1 & 1 & 3 & 3 \\
$F_{\mathrm{RF} 6}$ & 0.33 & 1 & 1 & 0.5 & 1 & 1 & 3 & 3 \\
$F_{\mathrm{RF} 7}$ & 0.20 & 0.33 & 0.33 & 0.25 & 0.33 & 0.33 & 1 & 1 \\
$F_{\mathrm{RF} 8}$ & 0.20 & 0.33 & 0.33 & 0.25 & 0.33 & 0.33 & 1 & 1 \\
\hline
\end{tabular}

Eigenvalue $=8.11$.

$\mathrm{CI}=0.0152$.

$\mathrm{CR}=0.0108$. 
achieved, the problem has to be studied again and the comparison matrix revised. Once achieved a good consistency, the principal eigenvector is calculated and normalized. This normalization is performed by dividing each element of the eigenvector by the sum of the values of its elements. The elements of this eigenvector are the values of the weighting factors. Table A.2 shows the weighting factors obtained starting from the pair wise comparison matrix of Table A.1. Table A.3 contains the pair wise comparison matrix for the aggravating factors obtained starting from the opinion of experts while the weights calculated by applying the AHP are given in Table A.4.

Table A.2. Importance for physical risk.

\begin{tabular}{lll} 
& Principal eigenvector & Priority vector \\
\hline$F_{\mathrm{RF} 1}$ & 0.7410 & 0.31 \\
$F_{\mathrm{RF} 2}$ & 0.2420 & 0.10 \\
$F_{\mathrm{RF} 3}$ & 0.2420 & 0.10 \\
$F_{\mathrm{RF} 4}$ & 0.4368 & 0.19 \\
$F_{\mathrm{RF} 5}$ & 0.2496 & 0.11 \\
$F_{\mathrm{RF} 6}$ & 0.2496 & 0.11 \\
$F_{\mathrm{RF} 7}$ & 0.0958 & 0.04 \\
$F_{\mathrm{RF} 8}$ & 0.0958 & 0.04 \\
\hline
\end{tabular}

Table A.3. Matrix of comparisons for the impact factor.

\begin{tabular}{llllllllllll}
\hline & $F_{\mathrm{FS} 1}$ & $F_{\mathrm{FS} 2}$ & $F_{\mathrm{FS} 3}$ & $F_{\mathrm{FS} 4}$ & $F_{\mathrm{FS} 5}$ & $F_{\mathrm{FR} 1}$ & $F_{\mathrm{FR} 2}$ & $F_{\mathrm{FR} 3}$ & $F_{\mathrm{FR} 4}$ & $F_{\mathrm{FR} 5}$ & $F_{\mathrm{FR} 6}$ \\
\hline$F_{\mathrm{FS} 1}$ & 1 & 4 & 4 & 1 & 1 & 3 & 3 & 4 & 4 & 3 & 3 \\
$F_{\mathrm{FS} 2}$ & 0.25 & 1 & 1 & 0.25 & 0.25 & 0.5 & 0.5 & 1 & 1 & 0.5 & 0.5 \\
$F_{\mathrm{FS} 3}$ & 0.25 & 1 & 1 & 0.25 & 0.25 & 0.5 & 0.5 & 1 & 1 & 0.5 & 0.5 \\
$F_{\mathrm{FS} 4}$ & 1 & 4 & 4 & 1 & 1 & 3 & 3 & 4 & 4 & 3 & 3 \\
$F_{\mathrm{FS} 5}$ & 1 & 4 & 4 & 1 & 1 & 3 & 3 & 4 & 4 & 3 & 3 \\
$F_{\mathrm{FR} 1}$ & 0.33 & 2 & 2 & 0.33 & 0.33 & 1 & 1 & 2 & 2 & 0.5 & 0.5 \\
$F_{\mathrm{FR} 2}$ & 0.33 & 2 & 2 & 0.33 & 0.33 & 1 & 1 & 2 & 2 & 0.5 & 0.5 \\
$F_{\mathrm{FR} 3}$ & 0.25 & 1 & 1 & 0.25 & 0.25 & 0.5 & 0.5 & 1 & 2 & 0.33 & 0.33 \\
$F_{\mathrm{FR} 4}$ & 0.25 & 1 & 1 & 0.25 & 0.25 & 0.5 & 0.5 & 0.5 & 1 & 0.33 & 0.33 \\
$F_{\mathrm{FR} 5}$ & 0.33 & 2 & 2 & 0.33 & 0.33 & 2 & 2 & 3 & 3 & 1 & 1 \\
$F_{\mathrm{FR} 6}$ & 0.33 & 2 & 2 & 0.33 & 0.33 & 2 & 2 & 3 & 3 & 1 & 1 \\
\hline
\end{tabular}

Eigenvalue $=11.24$.

$\mathrm{CI}=0.024$.

$\mathrm{CR}=0.016$. 
Table A.4. Importance for the impact factor.

\begin{tabular}{lll}
\hline & Principal eigenvector & Priority vector \\
\hline$F_{\mathrm{FS} 1}$ & 1.0000 & 0.18 \\
$F_{\mathrm{FS} 2}$ & 0.2136 & 0.04 \\
$F_{\mathrm{FS} 3}$ & 0.2136 & 0.04 \\
$F_{\mathrm{FS} 4}$ & 1 & 0.18 \\
$F_{\mathrm{FS} 5}$ & 1 & 0.18 \\
$F_{\mathrm{FR} 1}$ & 0.33928 & 0.06 \\
$F_{\mathrm{FR} 2}$ & 0.33928 & 0.06 \\
$F_{\mathrm{FR} 3}$ & 0.21601 & 0.04 \\
$F_{\mathrm{FR} 4}$ & 0.1895 & 0.04 \\
$F_{\mathrm{FR} 5}$ & 0.47833 & 0.09 \\
$F_{\mathrm{FR} 6}$ & 0.47833 & 0.09 \\
\hline
\end{tabular}

\section{References}

Barbat, A. H. and Cardona O. D.: 2003, Vulnerability and disaster risk indices from engineering perspective and holistic approach to consider hard and soft variables at urban level, IDB/IDEA Program on Indicators for Disaster Risk Management, http://idea.unalmzl. edu.co, Universidad Nacional de Colombia, Manizales.

Blaikie, P., Cannon, T., Davis, I., and Wisner, B.: 1996, Vulnerability, the Social Environment of the Disasters (in Spanish), La Red de Estudios Sociales en Prevención de Desastres en América Latina, La RED/ITDG, Bogota.

Cannon, T.: 1994, Vulnerability analysis and the explanation of Natural Hazards, In: A. Varley (ed.), Disasters Development and Environment, Chichester: Wiley.

Cardona, O. D.: 1996, Environmental management and disaster prevention: two associated topics (in Spanish), In: M. A. Fernández. (ed), Cities in Risk (in Spanish), USAID: La RED.

Cardona, O. D.: 2001, Holistic evaluation of the seismic risk using complex dynamic systems (in Spanish), PhD Thesis, Technical University of Catalonia, Barcelona, Spain.

Cardona, O. D.: 2004, The need for rethinking the concepts of vulnerability and risk from a holistic perspective: a necessary review and criticism for effective risk management, In: G. Bankoff, G. Frerks \& D. Hilhorst (eds), Mapping Vulnerability: Disasters, Development and People, London, UK: Earthscan Publishers.

Cardona, O. D. and Barbat, A. H.: 2000, The Seismic Risk and its Prevention (in Spanish), Calidad Siderúrgica, Madrid, Spain.

Cardona, O. D. and Hurtado J. E.: 2000. Holistic seismic risk estimation of a metropolitan center, in Proceedings of 12th World Conference of Earthquake Engineering, Auckland, New Zeland.

Carreño M. L., Cardona O. D. and Barbat A. H.: 2005, In: A. H. Barbat (ed.), System of Indicators for the Risk Evaluation (in Spanish). Monographs of Earthquake Engineering, IS-52, International Center for Numerical Methods in Engineering (CIMNE), Barcelona, España.

Chambers, R.: 1989, Vulnerability, coping and policy, IDS Bulletin No. 20, Institute of Development Studies, Sussex.

Coburn, A. and Spence, R.: 1992, Earthquake Protection, John Wiley \& Sons Ltd, Chichester, UK. 
Douglas, M. and Wildavsky, A.: 1982, Risk and Culture: An Essay on the Selection of Technological and Environmental Dangers, University of California Press, Berkeley.

Dynes, R. R. and Drabek, T. E.: 1994, The structure of disaster research: its policy and disciplinary implications, International Journal of Mass Emergencies and Disasters 12, 25-23.

FEMA: 1999, Earthquake Loss Estimation Methodology, HAZUS, National Institute of Building Science for Federal Emergency Management Agency, Washington.

ICC/CIMNE: 2004, An Advanced Approach to Earthquake Risk Scenarios with Applications to Different European Towns, WP08, Application to Barcelona, RISK-UE Project.

JRC-EC: 2002, State-of-the-art Report on Current Methodologies and Practices for Composite Indicator Development, Applied Statistics Group, Joint Research Centre, European Commission, Ispra, Italy.

JRC-EC: 2003, First Workshop on Composite Indicators of Country Performance, Applied Statistics Group, Joint Research Centre, European Commission, Ispra, Italy.

Karlsson J.: 1998, A systematic Approach for Prioritizing Software Requirements, Ph.D. dissertation No.526, Linkoping, Sverige.

Kasperson, R. E., Renn, O., Slovic, P., Brown, H. S., Emel, J., Goble, R., Kasperson, J. X., and Ratick, S.: 1988, The social amplification of risk: A conceptual framework, Risk Analysis 8(2), 177-187.

Kates, R. W.: 1971, Natural hazard in human ecological perspective: hypotheses and models, Economic Geography 47(3), 438-451, Clark University.

Lavell, A.: 1996, Environmental degradation, risk and urban disaster. Problems and concepts: towards the definition of a research schedule (in Spanish), In: M. A. Fernández (ed.), Cities in Risk (in Spanish), USAID: La RED.

Mansilla, E.: 1996, (ed.), Disasters: A Model to Construct, La RED, Lima, Perú.

Maskrey, A.: 1994, Community and disasters in Latin America: Intervention strategies (in Spanish), In: A. Lavell (ed.), Living at Risk: Vulnerable Communities and Disaster Prevention in Latin America (in Spanish), Bogota Colombia: LA RED Tercer Mundo Editores.

Masure, P.: 2003, Variables and indicators of vulnerability and disaster risk for land-use and urban or territorial planning, IDB/IDEA Programa de Indicadores para la Gestión de Riesgos, http://idea.unalmzl.edu.co, Universidad Nacional de Colombia, Manizales.

Palmlund, I.: 1989, The Case of Estrogens: An Inquiry Into Social Risk Evaluation, Unpublished doctoral dissertation, Clark University.

Quarantelli, E. L.: 1988, Disaster studies: an analysis of the social historical factor affecting the development of research in the area, International Journal of Mass Emergencies 5(3), 285310.

Rayner, S.: 1992, Cultural theory and risk analysis, In: S. Krimsky \& D. Golding (eds), Social Theories of Risk, West Port, CT: Praeger.

Saaty, T. L.: 1987, The analytic hierarchy process: what it is and how it is used, Mathematical Modeling 9, 161-176.

Saaty, T. L. and Vargas, L. G.: 1991, Prediction, Projection, and Forecasting: Applications of the Analytical Hierarchy Process in Economics, Finance, Politics, Games, and Sports, Kluwer Academic Publishers, Boston, USA.

Saaty, T. L.: 2001, Decision Making for Leaders the Analytic Hierarchy Process for Decisions in a Complex World, Pittsburgh RWS, USA.

Susman, P., O'Keefe, P. and Wisner, B.: 1984, Global Disasters: A Radical Interpretation, In: K. Hewitt (ed.): 1984, Interpretations of Calamity. Allen \& Unwin, Boston, MA.

UNDRO: 1980. Natural Disasters and Vulnerability Analysis, Report of Experts Group Meeting, UNDRO, Geneva. 
Universidad de Los Andes: 2005, Seismic risk and losses scenarios for Bogotá, D.C. (in Spanish), Centro de Estudios sobre Desastres y Riesgos CEDERI, Alcaldía Mayor de Bogotá, Dirección de Prevención y Atención de Emergencias, DPAE, Bogotá, Colombia. Wesgate, K. N. and O'Keefe, P.: 1976, Some definitions of disaster, paper No. 4, Disaster Research Unit, University of Bradford.

Wijkman, A. and Timberlake, L.: 1984, Natural Disasters: Act of God or Acts of Man, Earthscan, Washington.

White, G. F.: 1964, Choice of adjustment of floods, Research Paper 93, Department of Geography, University of Chicago.

Whitman, R. V.: 1973, Damage Probability Matrices for Prototype Buildings, Structures Publication 380. Department of Civil Engineering, Massachusetts Institute of Technology, Boston, Massachusetts.

Wilches-Chaux, G.: 1989, Disasters, Ecologism and Professional Education (in Spanish), SENA, Popayán, Colombia.

Wisner, B.: 1993, Disaster vulnerability: scale, power and daily life, GeoJournal 30(2), $127-140$.

Zapata, R.: 2004, personal communication in Washington. 